\title{
Diffusion of Wet Season (T. Aman) Rice Cultivars under Changed Environment in Northwest Bangladesh
}

\author{
M J Kabiri', M A Islam¹, M C Rahman¹, M S Rahaman'1, M S Kabir ${ }^{2}$ and M A B Siddique ${ }^{1}$
}

\begin{abstract}
Northwestern part of Bangladesh plays an important role to supply rice for national food security. However, wet season (WS) rice cultivation in the area is highly vulnerable to moisture stress and severe pest infestation. Therefore, it is very much important to evaluate the adoption situation of wet season rice cultivars and their drivers and drawbacks of adoption in order to delineate the possible ways of rapid dissemination of modern rice varieties to cope with the existing vulnerability and minimize yield gap. Two important wet season rice-growing districts, namely Rangpur and Dinajpur were selected purposively for the study. Focus group discussion (FGD) and key informant interview (KII) were conducted using semi-structured questionnaire to gather qualitative and quantitative data for the study. In addition, structured questionnaire was used in the FGD for generating data on input use patterns, outputs and seasonal variability of yield and price of different rice cultivars for estimating costs and returns. The findings of the study reveal that farmers mainly adopted exotic WS rice cultivars to reduce unexpected yield loss due to abiotic and biotic stresses. Diffusion status of exotic cultivars was ranged between $76-85 \%$ of total WS rice area in the study locations. The drivers of widespread diffusion of exotic cultivars are stability in yield performance, compatibility to fit into local cropping systems, potentiality to recover from biotic and abiotic stresses and ensured market demand. However, farmers are dreaming for higher yield potential and more stress tolerant cultivars for fitting into two and three crops-based systems in the areas. Rice breeders may use the findings of this study to develop and disseminate suitable rice cultivars for the northwestern part of the country.
\end{abstract}

Key words: Exotic rice cultivars, adoption drivers and constraints, abiotic and biotic stresses, adaptation strategies, varietal preferences, diffusion model.

\section{INTRODUCTION}

Bangladesh is currently self-sufficient in producing its staple food rice. Northwest Bangladesh is one of the most prominent corner stones in supply chain of rice production in the country. Although dry (Boro) season (DS) irrigated rice and wet season (WS) rain-fed low land rice jointly contribute in the value chains; however, share in value chains of WS rice is largely higher than that of DS rice. Additionally, straw of WS rice is very important to household for fuel and cattle feed. The country is highly vulnerable to climate change due to its geographical location, high population density and low adaptive capacity of people (Kabir et al. 2016). It has been projected that extreme weather events such as drought, cyclone, heavy rainfall, flood and intrusion of saline water will be more frequent and intense under changed environment (WB, 2013). Rahman et al. (2017) reported that unfavourable conditions might be aggravated in developing countries like Bangladesh. Therefore, rain-fed rice cultivation, in the country particularly in its northwest part, has become highly vulnerable. On the other hand, population of this country is projected to be 215 million by 2050 and country will have to produce additional 10.8 million ton rice to meet food grain requirement of increasing population from the decreasing natural resources including arable areas (Hussain, 2011). In this

\footnotetext{
${ }^{1}$ Agricultural Economics Division and 2Director General, BRRI, Gazipur 1701, Corresponding Author's E-mail: jkabirbrri@yahoo.com
} 
respect, the government in its seventh fiveyear plan introduced vertical extension approach for food production by enhancing cropping intensity and individual crop yield in the northwest Bangladesh.

Accelerating genetic gain, location specific varieties, minimizing yield gap and curtailing adoption lag could be options to alleviate the barriers of achieving the target (Kabir, 2015). Therefore, assessing farmers' perception about climate change, their adaptation options for wet season rain-fed low land rice, drivers and drawbacks of adoption of WS rice cultivars are important. However, none of the study was found to address the issues particularly in northwest Bangladesh where farmers adopted some exotic modern rain-fed low land rice cultivars entered in the frontier regions of Bangladesh from India through cross border seed exchange between farmers. The area coverage of the exotic cultivars in comparison to that of indigenous ones was very high in the northwest Bangladesh. Reasons behind adoption lag of indigenous/modern varieties are not always very clear. However, it is needed to disseminate these indigenous/modern varieties in those areas. Thus, a study to develop a diffusion model for curtailing adoption lags through in-depth evaluation of adoption status of varieties and their criteria and constraints and factors facilitated adoption deserve due attention.

\section{Specific Objectives}

Specific objectives of the study were to:

- Delineate diffusion status of wet season rice cultivars under changed environment

- Identify drivers and drawbacks of adoption of different rice cultivars

- Draw a rapid diffusion model for potential rice cultivars.

\section{METHODOLOGY}

Qualitative and quantitative data were collected from primary and secondary sources for the study. Quantitative data such as block wise adoption of different wet season rice varieties and their yield under farmers' and BRRI recommended management on demonstration plots for the last decade (20082018) were collected from Agriculture Office and the Department of Agricultural Extension (DAE). As the study requires detailed and in depth information about adoption of native, exotic and hybrid cultivars, two representative sub districts were purposively selected as location of case study viz Khansama of Dinajpur and Pirganj of Rangpur district where adoption of exotic cultivars in the locations were very high. Farm level data on farmers' perception of change in climate, their adaptation option for WS rice cultivation, and drivers and drawbacks of adoption of different WS rice cultivars and phenotype of dreaming WS rice cultivars were collected through focus group discussion (FGD). In total 22 FGDs were conducted in 22 unions of the selected subdistricts using an open ended pre-structured questionnaire. In total 660 key informants i.e., 10 from each of 66 blocks of 22 unions. In addition, a structured questionnaire was used in the FGD for generating data on input use patterns, price of inputs and outputs and seasonal variability of yield and price of different rice cultivars for estimating costs and returns of the rice cultivars. Furthermore, farmers were interviewed individually using a small structured questionnaire to delineate diffusion level of different WS rice cultivars in the study locations. Moreover, an expert panel interview with DAE personnel including SubAssistant Agriculture Officer (SAAO), Agriculture Extension Officer, Additional Agriculture Officer and Upazila Agriculture Officer were conducted in each sub-district to identify drivers and drawback of adoption of WS rice cultivars, and validate farmer's observation. Finally, an in-depth discussion was carried out with the expert panel members regarding reduction of adoption lag for the newly released potential rice cultivars. Both 
the qualitative and quantitative data were analyzed following descriptive statistics.

\section{RESULTS AND DISCUSSION}

\section{Description of study location}

Proportion of different farm household types in Pirganj and Khanshama is consistent with national average percentage of different farm types (BBS, 2017). Over $80 \%$ of total arable areas in the study locations are high to medium high lands, which are mostly used for two or three crops systems. Therefore, cropping intensity in the areas is largely higher (about 250\%) than that of national (192\%) average (BBS, 2017) (Table 1 ). Despite over $80 \%$ of total arable area is high to medium high land in both the locations; however, nearly half $(45 \%)$ of the areas in Pirganj used for Rice-Fallow-Rice cropping pattern, indicating that non-rice crop areas are used for rice cultivation in dry season (DS) in the location. On the other hand, about $76 \%$ of total arable areas allocated for 'rice, non-rice' cropping systems (Table 2). The land topography and land use pattern clearly indicates that there are substantial opportunities for diffusion of higher yield potential short duration WS cultivars in the locations.

Table 1. Basic agricultural statistics of Khansama under Dinajpur and Pirganj under Rangpur district.

\begin{tabular}{|c|c|c|c|c|}
\hline Item & Khansama & $\%$ & Pirganj & $\%$ \\
\hline \multicolumn{5}{|c|}{ Agricultural household (No.): } \\
\hline Landless & 9,844 & 26.4 & 13,211 & 15.2 \\
\hline Marginal & 11,296 & 30.3 & 26,966 & 31.0 \\
\hline Small & 11,950 & 32.1 & 35,653 & 41.0 \\
\hline Medium & 3,691 & 9.9 & 10,157 & 11.7 \\
\hline Large & 439 & 1.2 & 900 & 1.0 \\
\hline Total & 37,220 & 100.0 & 86,887 & 100.0 \\
\hline \multicolumn{5}{|l|}{ Land type (ha) } \\
\hline High land & 4,500 & 29.3 & 13,705 & 33.5 \\
\hline Medium high land & 8,111 & 52.8 & 22,028 & 53.8 \\
\hline Medium low land & 2,750 & 17.9 & 970 & 2.4 \\
\hline Low land & - & - & 4,229 & 10.3 \\
\hline Total land area & 15,361 & 100.0 & 40,932 & 100.0 \\
\hline \multicolumn{5}{|l|}{ Land use statistics (ha) } \\
\hline Single cropped area & 328 & 2.13 & 1,010 & 3.07 \\
\hline Double cropped area & 5,290 & 34.43 & 21,450 & 65.39 \\
\hline Triple cropped area & 9,743 & 63.43 & 8,272 & 25.21 \\
\hline Quadruple cropped area & - & - & 2,068 & 6.30 \\
\hline Net cropped area & 15,361 & 100 & 32,800 & 100 \\
\hline Total cropped area & 40,139 & - & 76,998 & - \\
\hline Cropping intensity (\%) & 261 & - & 251 & - \\
\hline
\end{tabular}

Source: DAE, 2017-18 
Table 2. Major cropping pattern of Khansama and Pirganj upazilas.

\begin{tabular}{lccccc}
\hline \multirow{2}{*}{ Dominant cropping pattern } & \multicolumn{2}{c}{ Khansama upazila } & & \multicolumn{2}{c}{ Pirganj upazila } \\
\cline { 2 - 3 } \cline { 5 - 6 } & Area (ha) & $\%$ & & Area (ha) & $\%$ \\
\hline Boro-Fallow-T. Aman & 3,700 & 24 & & 14,760 & 45 \\
Maize-Fallow-T. Aman & 1,590 & 10 & & - & - \\
Potato-Maize-Fallow-T. Aman & 2,396 & 16 & & - & - \\
Wheat-Jute-T. Aman & 2,150 & 14 & & - & - \\
Potato-Boro-T. Aman & - & - & 4,920 & 15 \\
Potato-Jute-T. Aman & - & - & 2,296 & 7 \\
Potato-Aus-T. Aman & - & - & & 1,640 & 5 \\
Vegetables-Seedbed-Vegetables & - & - & & 1,320 & 4 \\
Vegetables-Vegetables-T. Aman & 534 & 3 & - & - \\
Garlic-Vegetables-T. Aman & 500 & 3 & & - & - \\
Wheat-Maize-T. Aman & 490 & 3 & & - & - \\
Mustard/Potato-Vegetables-Aus-T. Aman & - & - & & - & 80 \\
Major cropping pattern total & - & 74 & & - & - \\
\hline
\end{tabular}

Source: DAE, 2017-18

Climate change perception and adaptation strategies

Farmers in group discussion said that they observed changes in climate particularly rise in temperature over the years, decreased spread of rainfall (no rainfall in some months), shifted delay of monsoon months about 15-25 days, unpredictable rainfall pattern, increasing extreme weather events, particularly heavy rainfall, floods and droughts. Likewise, Nishat and Mukherjee (2013) reported that the maximum $\left(0.87^{\circ} \mathrm{C}\right.$ and $\left.0.42^{\circ} \mathrm{C}\right)$ and minimum $\left(0.45^{\circ} \mathrm{C}\right.$ and $\left.0.52{ }^{\circ} \mathrm{C}\right)$ temperature is observed a prominent rise in over the last few decades. Farmers observed increased infestation of insects and pest in the WS rice in the locations. Key informants reported that potentiality of performance of some rice varieties, for instance BR11 has become considerably unsustainable under changed environment due mainly to its higher proneness to pest and less tolerance to moisture stress and cold at the panicle emerging stage. Therefore, farmers undertook planned and local adaptation option including changes in rice cultivars, application of supplementary irrigation and double transplanting technique. Farmers have adopted some higher yield potential exotic cultivars, for instance Guti Swarna, Swarna5 and Mamun Swarna because of sustainable performance of the cultivars despite stress environment.

\section{Adoption status of wet season rice cultivars}

Diffusion status of exotic inbred WS rice cultivars in Khanshama was substantially dominant (range between $79-85 \%$ of total WS rice area) with an upward trend over the last decade. Among the exotic inbred cultivars, status of Guti Swarna was most dominant, however, its adoption decreased slightly to $47 \%$ in 2018 from $57 \%$ in 2008. Similarly, adoption of BRRI cultivars during the decade decreased to $8 \%$ in 2018 from $15 \%$ in 2008. In the contrary, diffusion of other exotic cultivars, in particular Mamun Swarna and Swarna5 increased notably to $32 \%$ of total area of WS rice in 2018 from 13\% in 2008. Similarly, adoption of exotic hybrid cultivars increased to about $6 \%$ of total area in 2018 from only less than one percent in 2008 (Table 3). Farmers in group discussion informed that long duration cultivars, for instance Guti Swarna, BR11 and others were replaced mainly by short duration cultivar (25-30 days shorter) for instance Mamun Swarna and hybrid as well as by Swarna5 (medium slender and slightly shorter lifecycle) 
Table 3. Adoption trend of wet season rice cultivars during from 2008 to 2018 in Khanshama, Dinajpur.

\begin{tabular}{lccccccccccc}
\hline Variety & 2008 & 2009 & 2010 & 2011 & 2012 & 2013 & 2014 & 2015 & 2016 & 2017 & 2018 \\
\hline Exotic: & & & & & & & & & & & \\
Guti Swarna & 57.0 & 56.8 & 57.2 & 51.5 & 42.6 & 41.7 & 51.5 & 51.2 & 45.7 & 46.8 & 42.2 \\
Mamun Swarna & 12.5 & 14.1 & 12.0 & 14.4 & 19.5 & 19.3 & 16.4 & 17.1 & 19.4 & 19.9 & 18.7 \\
Swarna5 & 0.3 & 1.5 & 2.6 & 5.3 & 10.0 & 9.9 & 6.9 & 7.7 & 12.3 & 13.3 & 17.2 \\
Other Indian & 9.6 & 7.9 & 9.5 & 11.2 & 10.9 & 12.1 & 5.6 & 5.4 & 3.7 & 4.2 & 6.4 \\
All Indian & 79.4 & 80.2 & 81.3 & 82.5 & 83.0 & 83.0 & 80.4 & 81.4 & 81.1 & 84.2 & 84.5 \\
Hybrid & 0.4 & 0.5 & 0.6 & 0.6 & 0.7 & 0.7 & 5.9 & 5.0 & 5.2 & 4.5 & 5.8 \\
Indigenous: & & & & & & & & & & & \\
BR11 & 8.5 & 7.6 & 6.6 & 5.7 & 5.4 & 4.8 & 4.6 & 4.5 & 1.5 & 0.7 & 0.05 \\
BRRI dhan49 & 6.5 & 6.9 & 7.8 & 6.8 & 6.4 & 6.7 & 4.8 & 5.2 & 4.3 & 3.6 & 2.6 \\
BRRI dhan51 & 0.0 & 0.0 & 0.0 & 0.0 & 0.0 & 1.4 & 0.7 & 0.7 & 2.1 & 2.8 & 3.1 \\
BRRI dhan52 & 0.0 & 0.0 & 0.0 & 0.0 & 0.0 & 1.4 & 0.9 & 0.9 & 1.9 & 1.6 & 1.8 \\
Other BRRI & 1.3 & 1.2 & 0.9 & 1.1 & 1.1 & 0.5 & 0.6 & 1.1 & 2.0 & 1.3 & 0.5 \\
All BRRI & 14.9 & 14.5 & 14.4 & 12.5 & 11.7 & 14.3 & 11.1 & 11.3 & 9.8 & 8.7 & 8.0 \\
& & & & & & & & & & & \\
All MVs & 96.1 & 96.4 & 97.3 & 96.7 & 96.6 & 98.5 & 98.1 & 98.9 & 98.0 & 98.7 & 99.3 \\
LVs & 3.9 & 3.6 & 2.7 & 3.3 & 3.4 & 1.5 & 1.9 & 1.1 & 2.0 & 1.3 & 0.7 \\
Overall & 100 & 100 & 100 & 100 & 100 & 100 & 100 & 100 & 100 & 100 & 100 \\
\hline Source: DAE Khan & & & & & & & & & &
\end{tabular}

Source: DAE, Khanshama

It is partly because of the short duration cultivars facilitate sowing of garlic and maize on time and introduce a rice crop in cropping pattern in early wet season (EWS), and partly because of potentiality of the cultivars to perform consistently across different seasonal conditions. On the other hand, farmers in the group discussion informed that adoption of BRRI cultivars decreased to $8 \%$ of total WS rice in 2018 from over $60-65 \%$ in 2000 is mainly because of their poor performance under changed climate conditions and stress environment. Table 4 presents that on average adoption of exotic inbred cultivars in 2018 was about $76 \%$ of total area of WS rice in Khanshama, which is slightly lower than that of $(84 \%)$ reported by DAE (Table 3$)$. It was found that diffusion of exotic inbred cultivars was highly dominant (ranges between $71-77 \%$ of total WS rice area of respective union) across unions in Khanshama. Among the exotic cultivars, on average adoption of Guti Swarna was higher (about $40 \%$ of total WS rice area) followed by Mamun Swarna (about 18\%) and Swarna5 (about 14\%). However, there were considerable variation in adoption of Guti Swarna (ranges between 19-48\%), Mamun Swarna (ranges between 8-34\%) and Swarna5 (ranges between 9-21\%) among unions. In the contrary, on average adoption of BRRI varieties were range between $15-17 \%$ of total areas of respective union. Among BRRI varieties, BRRI dhan 51 covered about $5 \%$ of total WS rice area in Khanshama followed by BRRI dhan49 (4\%), BRRI dhan52 (3\%). Besides, a few areas $(1.5 \%)$ were covered by other BRRI varieties (BRRI dhan33, BRRI dhan34, BRRI dhan57, BRRI dhan62, BRRI dhan71 and BRRI dhan75). In addition, hybrid rice covers about $3-12 \%$ of total area of the respective union with an average of $6 \%$ of total WS rice area in Khansama. 
Table 4. Union-wise adoption of different wet season rice cultivars in Khanshama, Dinajpur, 2018.

\begin{tabular}{lccccccc}
\hline Variety/Location & Alokjhari & Angerpara & Bhabki & Goaldehi & Khamarpara & Vhervery & Overall \\
\hline Exotic: & & & & & & & \\
Guti Swarna & 47.7 & 39.5 & 38.8 & 59.0 & 37.2 & 19.1 & 40.2 \\
Mamun Swarna & 8.1 & 18.4 & 15.7 & 10.1 & 19.1 & 34.1 & 17.6 \\
Swarna5 & 20.6 & 15.2 & 16.7 & 8.8 & 12.9 & 12.4 & 14.4 \\
Other Indian & 3.2 & 4.1 & 4.6 & 1.6 & 1.5 & 6.0 & 3.5 \\
All Indian & 79.7 & 77.1 & 75.9 & 79.5 & 70.7 & 71.7 & 75.8 \\
Hybrid & 3.3 & 3.9 & 6.6 & 2.9 & 12.1 & 9.2 & 6.3 \\
Indigenous: & & & & & & & \\
BR11 & 2.8 & 2.6 & 4.8 & 4.5 & 2.3 & 2.3 & 3.2 \\
BRRI dhan49 & 2.8 & 4.7 & & 2.5 & 5.5 & 5.7 & 4.2 \\
BRRI dhan51 & 5.4 & 5.0 & 5.1 & 5.7 & 3.8 & 4.0 & 4.8 \\
BRRI dhan52 & 3.4 & 3.2 & 4.1 & 2.7 & 3.0 & 2.8 & 3.2 \\
Other BRRI & 1.2 & 1.6 & 1.5 & 1.4 & 1.9 & 1.6 & 1.5 \\
All BRRI & 15.5 & 17.2 & 15.4 & 16.8 & 16.5 & 16.3 & 16.3 \\
Other MVs & 0.9 & 1.1 & 1.3 & 0.4 & 0.4 & 1.7 & 1.0 \\
All MVs & 99.3 & 99.2 & 99.1 & 99.7 & 99.7 & 98.8 & 99.3 \\
LVs & 0.7 & 0.8 & 0.9 & 0.3 & 0.3 & 1.2 & 0.7 \\
Overall & 100 & 100 & 100 & 100 & 100 & 100 & 100 \\
\hline SOUrce Fidd
\end{tabular}

Source: Field survey 2018.

Farmers in group discussion and expert panel members said that key driver of adoption of Mamun Swarna and hybrid was that those short duration cultivars facilitate early planting of local variety potatoes and garlic on time for about $25 \%$ of total arable area in Khanshama. Similarly, Swarna5 (5-7 days shorter than Guti Swarna) facilitates to planting DS crops on time and its medium slender grain is one of the most preferred rice varieties for the people in Khanshama (Table 4).

Table 5 presents adoption of Indian cultivars particularly Guti Swarna which was substantially high in the areas with an increasing trend during last decade. Adoption of exotic cultivars increased to about $75 \%$ of total area of WS rice in 2018 from 52\% in 2008. In the contrary, adoption of BRRI cultivars decreased to about $16 \%$ of total area of WS rice in 2018 from $34 \%$ in 2008. It was mainly because of decreased adoption of BR11 substantially due mainly to very poor performance of the cultivar in 2012. Similarly, adoption of Bina dhan7 also decreased to about $2 \%$ of total areas of WS rice from about $7 \%$ in 2008. It indicates that BR11 and Binadhan-7 were mainly replaced by Guti
Swarna. Besides, some high to medium high lands went under cultivation of short duration hybrid varieties (about 5\%) and slightly short duration Swarna5. On the other hand, some medium low to low lands used for cultivating submergence tolerant cultivars BRRI dha51 and BRRI dha52 (Table 3).

Farmers in group discussion and panel members of expert group discussion unanimously agreed that performance of Guti Swarna is sustainable across seasonal conditions, land types and management. Additionally, despite longer growth duration it is possible to planting as dry season (DS) crops on time after harvesting Guti Swaran if the rice is transplanted early. On the other hand, farmers informed that currently performance of BR11 is not only unsustainable (seasonal variation in yield is very high) but also the cultivar is not matured for harvesting (mild photoperiod sensitive) for timely planting of DS crops despite transplanting early. The respondents also said that environmental stresses (biotic and abiotic) tolerance and suitability for three crops-based systems was pivotal for substantial diffusion of exotic cultivars. 
Table 6 shows that on average adoption of exotic inbred cultivars was about $71 \%$ of total area of WS rice, of which adoption of Guti Swarna was about 69\% in Pirganj in 2018-19 which is consistent with adoption status of WS rice cultivars as reported by DAE (Table 5). On the contrary, adoption of BRRI cultivars was about $19 \%$ of total area of the Upazila. Among BRRI varieties, BRRI dhan52 was major one (about $6 \%$ ) and followed by BR11 (5\%), BRRI dhan51 (4\%) and BRRI dhan49 (1\%). Besides, a few areas $(2.6 \%)$ are used for cultivating other BRRI varieties including BRRI dhan33, BRRI dhan34, BRRI dhan57, BRRI dhan62, BRRI dhan71 and BRRI dhan75. Additionally, on average $5 \%$ of total area are being used for hybrid. It is also the cases that there was a notable variation in adoption status of exotic inbred varieties (range between 64-80\%) and BRRI cultivars (range between 15-25\%) among the unions in Khanshama (Table 6). Farmers in group discussion and expert panel members said that variation of adoption of cultivars among unions was mainly because of variation in topography and soil types of lands and cropping systems.

\section{Relative performance of cultivars}

Figure 1 presents performance of BRRI and Indian WS rice cultivars under farmers' and recommended practice during 2008-17, in Khanshama, Dinajpur. It was observed that over the last decade per hectare yield of BRRI cultivars was lower in range between 0.54-1.03 $\mathrm{t} \mathrm{ha}^{-1}$ and $0.20-0.37 \mathrm{t} \mathrm{ha}^{-1}$, respectively under farmers' and recommended practice (demonstration plots) than that of Indian cultivars even under farmers practice. On other words, exotic inbred cultivars gave at least one ton higher yield over BRRI cultivars under farmers' practice in most years across last decade. Similarly, performance of exotic cultivars under farmers' practice was far better (per hectare about half a ton yield advantage) than that of BRRI cultivars even under recommended practice in demonstration plots. Farmers in-group discussion and extension personnel highlighted that potentiality of performing better under stress environmental condition is one of the most important driver of substantial diffusion of exotic WS cultivars in Khanshama.

Table 5. Adoption trend of wet season rice cultivars, during 2008/099-2017-18 in Pirganj, Rangpur.

\begin{tabular}{llllllllllll}
\hline Variety/year & 2008 & 2009 & 2010 & 2011 & 2012 & 2013 & 2014 & 2015 & 2016 & 2017 & 2018 \\
\hline Exotic: & & & & & & & & & & & \\
Guti Swarna & 52.3 & 56.4 & 56.1 & 58.5 & 60.3 & 81.6 & 82.7 & 70.2 & 68.5 & 67.6 & 66.7 \\
$\begin{array}{l}\text { Other Indian } \\
\text { varieties }\end{array}$ & 0.0 & 0.4 & 0.8 & 0.0 & 0.0 & 0.0 & 0.0 & 2.8 & 2.8 & 5.0 & 8.2 \\
All Indian & 52.3 & 56.8 & 56.9 & 58.5 & 60.3 & 81.6 & 82.7 & 73.0 & 71.3 & 72.6 & 74.9 \\
Hybrid & 0.2 & 0.9 & 1.2 & 1.3 & 1.1 & 2.6 & 2.6 & 4.2 & 4.7 & 4.9 & 5.3 \\
Indigenous: & & & & & & & & & & & \\
BR11 & 33.5 & 30.6 & 28.5 & 23.9 & 22.9 & 4.4 & 4.4 & 5.8 & 4.3 & 3.0 & 4.0 \\
BRRI dhan49 & & & & 0.3 & 0.3 & 1.0 & 1.0 & 1.2 & 1.8 & 1.6 & 1.2 \\
BRRI dhan51 & & & & 1.9 & 1.8 & 1.1 & 1.1 & 1.0 & 1.4 & 4.2 & 3.0 \\
BRRI dhan52 & & & & 2.9 & 2.8 & 3.2 & 3.2 & 4.8 & 5.9 & 5.0 & 4.8 \\
Other BRRI & 0.6 & 1.1 & 3.1 & 2.1 & 2.0 & 1.1 & 0.7 & 1.7 & 1.6 & 1.6 & 2.6 \\
All BRRI & 34.1 & 31.7 & 31.6 & 31.1 & 29.8 & 10.8 & 10.4 & 14.4 & 15.0 & 15.5 & 15.5 \\
& & & & & & & & & & & \\
Binadhan-7 & 7.8 & 7.1 & 6.9 & 6.6 & 6.3 & 3.0 & 2.3 & 6.4 & 6.8 & 4.5 & 2.1 \\
All MVs & 94.4 & 96.4 & 96.5 & 97.5 & 97.5 & 98.0 & 98.1 & 97.9 & 97.8 & 97.4 & 97.8 \\
Local & 5.6 & 3.6 & 3.5 & 2.6 & 2.5 & 2.0 & 1.9 & 2.1 & 2.2 & 2.6 & 2.2 \\
Overall & 100 & 100 & 100 & 100 & 100 & 100 & 100 & 100 & 100 & 100 & 100 \\
\hline Source DAE, Pirg & & & & & & & & & &
\end{tabular}

Source: DAE, Pirganj 
Table 6. Union-wise adoption of different wet season rice cultivars in Pirganj, Rangpur, 2018-19.

\begin{tabular}{|c|c|c|c|c|c|c|c|c|c|c|c|c|c|c|}
\hline \multirow[b]{2}{*}{ 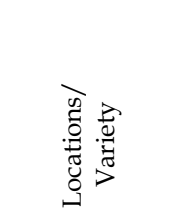 } & \multicolumn{6}{|c|}{ Exotic/Indian } & \multicolumn{7}{|c|}{ Indigenous } & \multirow[b]{2}{*}{$\bar{Z}$} \\
\hline & 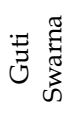 & 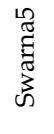 & 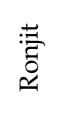 & $=\underset{\mathbb{Z}}{\stackrel{\Xi}{\Xi}}$ & 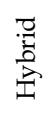 & $\underset{\vec{n}}{\vec{n}}$ & $\frac{\vec{a}}{\stackrel{a}{\Xi}}$ & 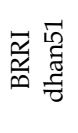 & 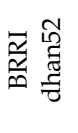 & 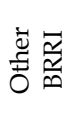 & 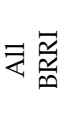 & $\stackrel{\stackrel{\Xi}{5}}{0} \sum^{\infty}$ & $\sum_{1}^{\infty}$ & \\
\hline Boroalampur & 63.2 & 3.0 & 4.9 & 71.1 & 6.5 & 5.6 & 1.0 & 4.8 & 5.7 & 2.9 & 20.0 & 1.6 & 0.7 & 100 \\
\hline Borodorga & 64.0 & & 3.0 & 67.0 & 5.7 & 7.0 & 1.1 & 1.1 & 6.0 & 0.6 & 15.9 & 8.1 & 3.5 & 100 \\
\hline Vedabari & 68.8 & 1.0 & 10.0 & 79.8 & 0.6 & 2.9 & 0.9 & 7.6 & 4.2 & 0.0 & 15.6 & 2.9 & 1.2 & 100 \\
\hline Chaitracol & 71.2 & 1.1 & 1.8 & 74.1 & $\begin{array}{c}10 . \\
5\end{array}$ & 1.2 & 1.1 & 4.7 & 5.3 & 2.5 & 14.9 & 0.3 & 0.1 & 100 \\
\hline Chatra & 72.0 & 1.2 & 1.3 & 74.5 & 3.4 & 4.1 & 1.3 & 4.7 & 7.4 & 4.2 & 21.6 & 0.4 & 0.2 & 100 \\
\hline Kabelpur & 78.1 & 1.1 & - & 79.2 & 3.5 & 2.6 & 1.2 & 3.5 & 5.8 & 2.4 & 15.4 & 1.4 & 0.6 & 100 \\
\hline Kumedpur & 73.7 & - & 1.5 & 75.2 & 4.8 & 3.8 & 1.1 & 6.3 & 4.4 & 2.3 & 17.9 & 1.5 & 0.7 & 100 \\
\hline Methipur & 64.3 & - & - & 64.3 & 3.5 & 6.3 & 1.3 & 2.5 & 6.7 & 4.8 & 21.7 & 7.4 & 3.2 & 100 \\
\hline Madonkhali & 70.7 & - & - & 70.7 & 3.5 & 9.4 & 1.0 & 5.1 & 8.1 & 1.0 & 24.7 & 0.8 & 0.3 & 100 \\
\hline Pachgachi & 64.0 & - & 4.0 & 68.0 & 5.8 & 5.2 & 2.1 & 3.6 & 5.4 & 8.2 & 24.6 & 1.1 & 0.5 & 100 \\
\hline Pirganj & 64.7 & - & 3.9 & 68.6 & 8.0 & $\begin{array}{c}12 . \\
0\end{array}$ & 1.5 & 1.1 & 5.6 & 1.3 & 21.6 & 1.3 & 0.5 & 100 \\
\hline Pourasava & 72.1 & - & 0.5 & 72.6 & 7.5 & 5.1 & 1.3 & 3.6 & 6.1 & 3.5 & 19.5 & 0.4 & 0.2 & 100 \\
\hline Ramnathpur & 67.5 & 0.8 & - & 68.3 & 4.9 & 3.5 & 1.1 & 5.2 & 6.2 & 0.4 & 16.4 & 7.4 & 3.2 & 100 \\
\hline Roypur & 67.2 & 0.9 & 1.0 & 69.1 & 2.7 & 5.5 & 0.8 & 4.5 & 5.1 & 3.4 & 19.2 & 6.3 & 2.7 & 100 \\
\hline Shanerhat & 66.8 & 0.9 & 1.1 & 68.8 & 5.5 & 4.4 & 1.2 & 3.8 & 7.6 & 2.1 & 19.0 & 4.7 & 2.0 & 100 \\
\hline Tukuria & 69.0 & 0.8 & - & 69.8 & 7.9 & 4.3 & 1.4 & 4.8 & 6.2 & 2.2 & 18.9 & 2.4 & 1.0 & 100 \\
\hline Overall & 68.6 & 1.2 & 3.0 & 71.3 & 5.3 & 5.2 & 1.2 & 4.2 & 6.0 & 2.6 & 19.2 & 3.0 & 1.3 & 100 \\
\hline
\end{tabular}

Source: Field Survey 2018

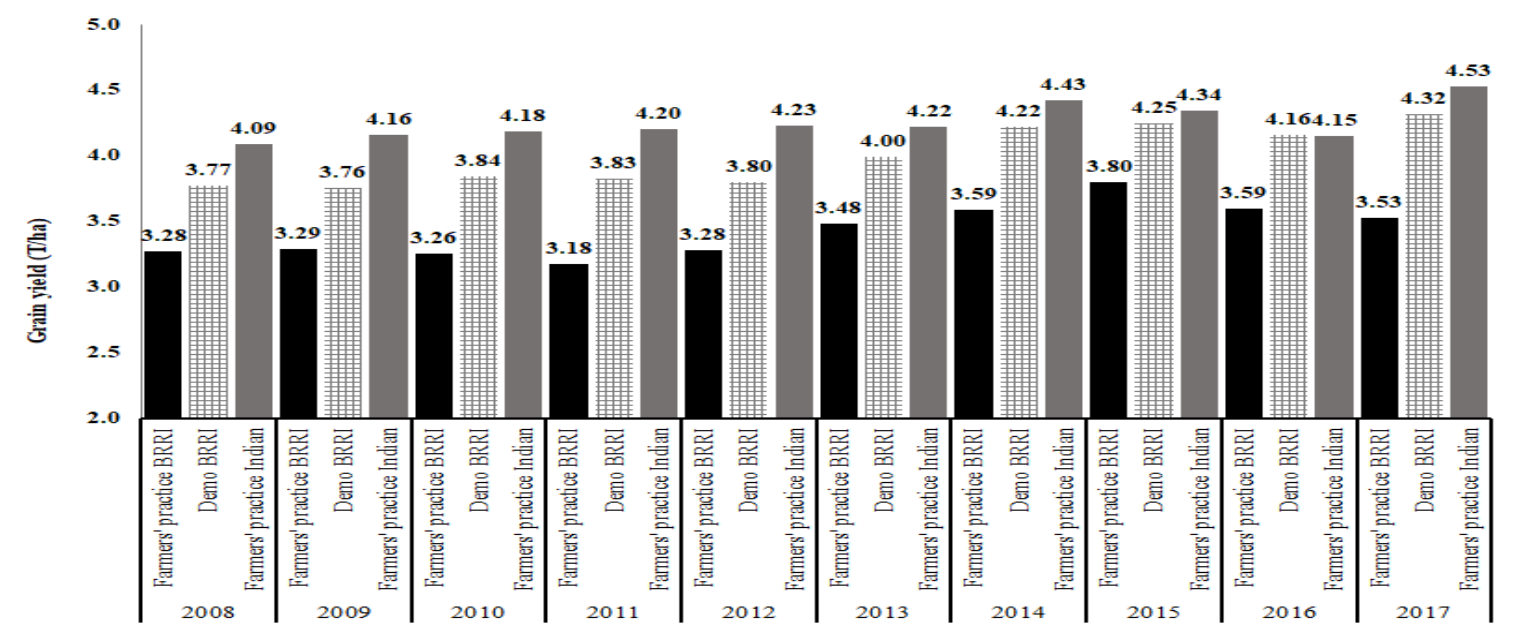

Fig. 1. Performance of BRRI and Indian WS rice cultivars under farmers' and recommended practice during 2008-17, in Khansama, Dinajpur. 
Figure 2. presents performance of BRRI and Indian WS rice cultivars under farmers' and recommended practice during 2008-17, in Pirganj, Rangpur. It was observed that yield of BRRI cultivars over the last decade was lower in range between $0.38-0.53 \mathrm{tha}^{-1}$ and $0.17-0.29 \mathrm{t}$ ha $^{-1}$ respectively under farmers' practice and recommended practice than that of Indian cultivars under farmers' practice. In other words, exotic cultivars gave per hectare nearly half ton yield advantage over BRRI cultivars under farmers' practice in last decade. Additionally, performance of exotic cultivars even under farmers' practice was far better (per hectare about quarter a ton yield advantage) than that of BRRI cultivars even under recommended practice in demonstration plots. Farmers and extension personnel thought that better performance was one of the vital drivers of substantial diffusion of exotic cultivars in Pirganj.

Drivers of adoption exotic varieties in wet season

Among the adopted exotic WS rice varieties, Guti Swarna is the most dominant in both the study locations, and Swarna5 and Mamun Swarna are the second and third most dominant varieties in Khanshama (Table 7). Additionally, Ronjit is cultivated in some areas of both the locations and Garson is cultivated in some areas in Khanshama alone. Table 7 presents drivers and drawbacks of adoption of the exotic variety in WS in the study location. Adoption drivers of WS rice varieties are typified following agronomic, economic, social and environmental criteria and are discussed below.

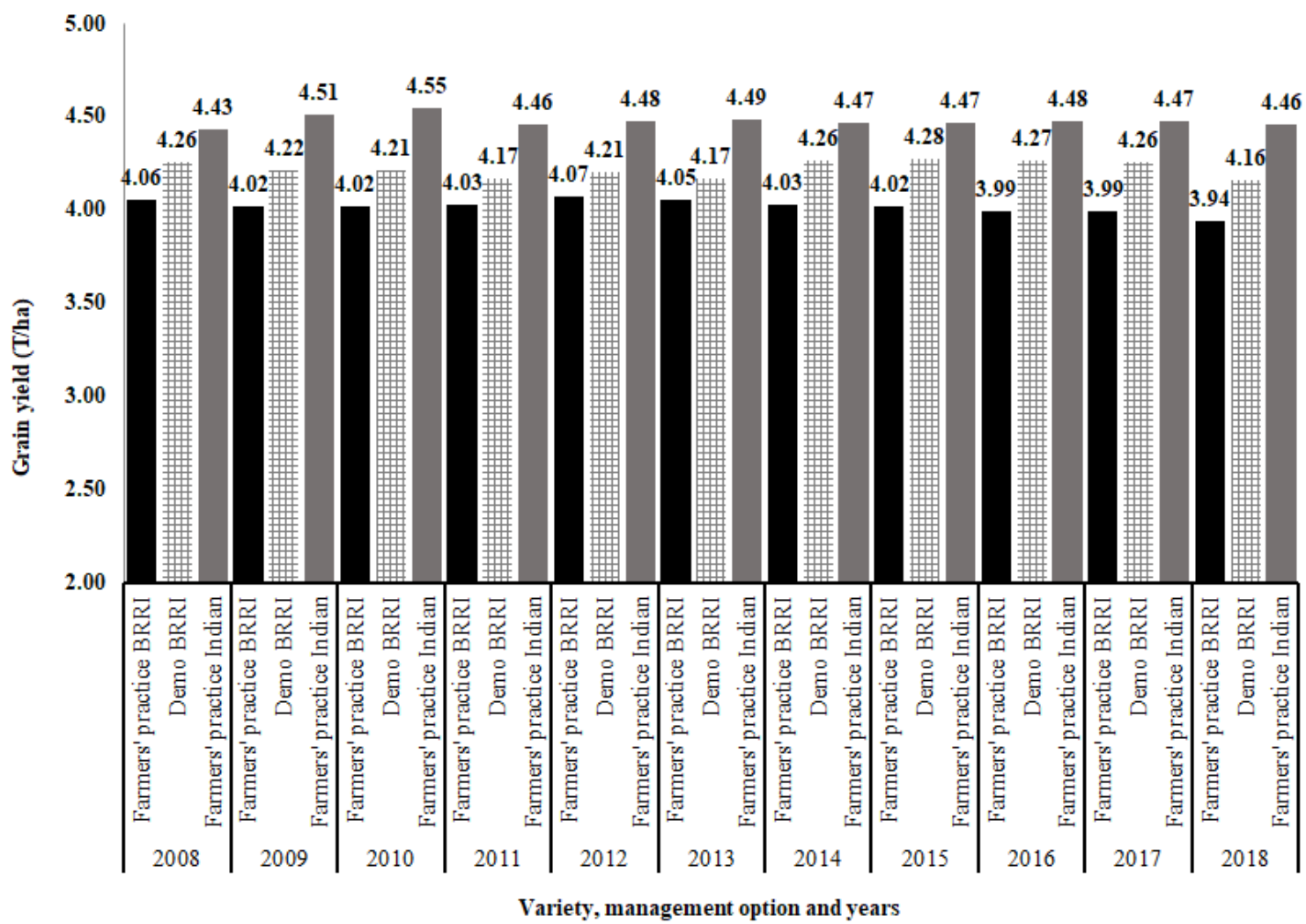

Fig. 2. Performance of BRRI and Indian WS rice cultivars under farmers' and recommended practice during 2008-2018, in Pirganj, Rangpur. 


\section{Agronomic drivers}

Most farmers in group discussion said that higher yield potential than the other WS rice varieties under typical seasonal condition, and stable performance despite seasonal weather variation (e.g., heat, cold and erraticism of rainfall) was the most important driver of dominance for exotic inbred cultivars (Guti Swarna, Swarna5/Suman Swarna and Mamun Swarna) in WS. In other words, most key informants reported that the exotic cultivars were potential to produce expected yield even under the worst seasonal conditions (Table 7; Fig. 3), which was the main reason of largescale adoption. Nevertheless, performance of BRRI varieties (BR11, BRRI dhan49 and BRRI dhan52) except the recently released ones (BRRI dhan71 and BRRI dhan75) substantially fluctuates, particularly due to moisture stress and cold before emerging panicles. For example, grain yield of exotic varieties ranges between 3.9-5.9 $\mathrm{t} \mathrm{ha} \mathrm{h}^{-1}$ across different seasonal conditions (good, typical and worst) while yield of BR11, BRRI dhan49, BRRI dhan52 and BRRI dhan51 decreased to less than $3 \mathrm{t} \mathrm{ha}^{-1}$ under worst season condition in particular due to infestation of pest, moisture stress, and dew as well as mild cold at panicle emerging time.
This sustainable performance of exotic cultivars is pivotal for large-scale diffusion in WS in survey areas was unanimously highlighted by both the expert panel members and key informant farmers (Table 7).

Moreover, majority of the key informants informed that exotic cultivars (Guti Swarna, Swarna5 and Mamun Swarna) not only have higher adaptive capacity to abiotic (floods, droughts and cold) and biotic (sheath blight, sheath rot, stem borer and leaf roller) stress but also, they are relatively less susceptible to some pest (BPH, tungro, ufra, ear cutter caterpillar and false smut), which are also crucial drivers for large-scale dissemination of those cultivars. Firstly, key informants reported that exotic cultivars consistently perform despite 5-7 days of natural flash flood submergence at vegetative stage as well as cold, moisture stress, heavy rain and storm at reproductive stage. In this regard, farmers said that cultivars recovered so quickly and fully from partial damage by flash flood submergence when MOP was top-dressed immediately after draining out the stagnant water from the fields, consequently reduced yield compensation.

- GutiSwarna Swarna 5 Mamun Swarn

F BRRI dhan52 NBR11 \& BRRIdhan49

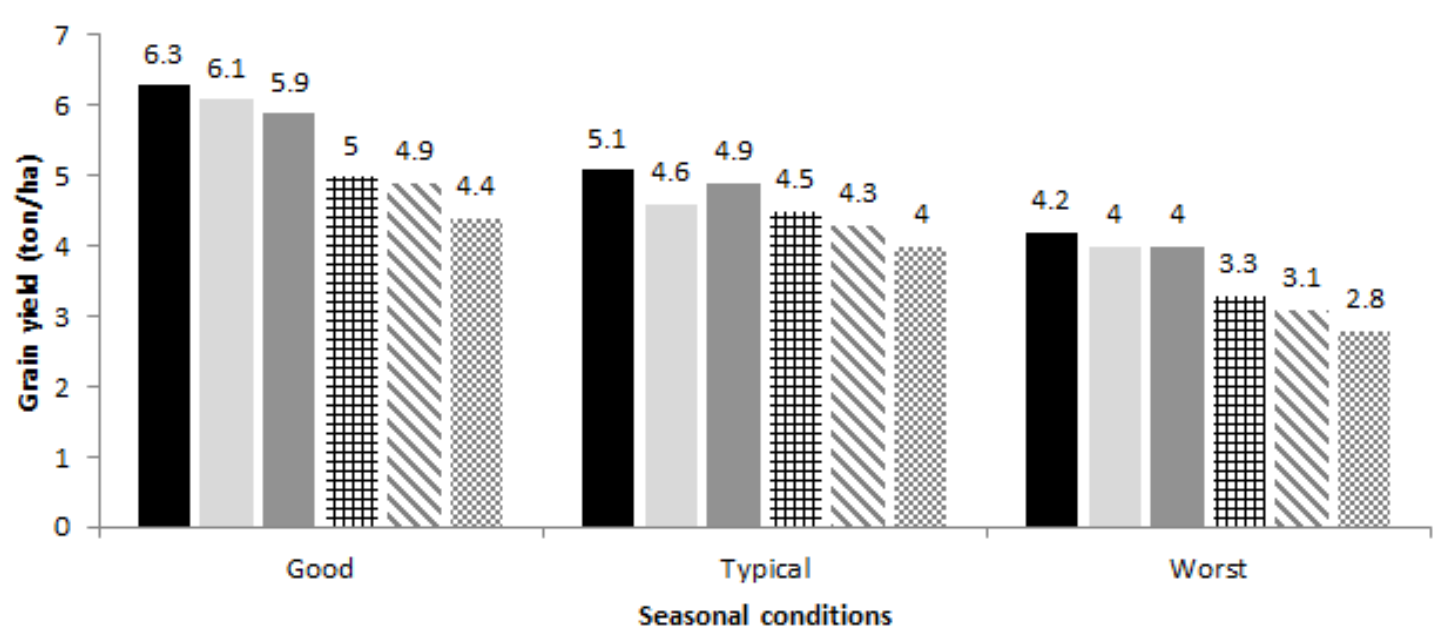

Fig. 3. Performance of different wet season rice cultivars under different seasonal conditions in study locations. 
Besides, despite moisture stress and cold, panicles of those cultivars emerge quickly and fully except Swarna5, which is somewhat, drought susceptible. In the contrary, despite application of supplementary irrigation, BR11 and BRRI dhan49 and BRRI dhan52 were unable to exert panicle fully because of the beginning of winter (cold or even fall dew at night), consequently decreased yield substantially. Moreover, BR11 and BRRI dhan49 are highly vulnerable to floods at transplanting and tillering stages (Table 7).

Secondly, farmers in group discussion said that although, exotic varieties were highly prone to sheath blight and sheath rot, stem borer and leaf roller; nevertheless, they recovered from even severe infestation of such pest so quickly and fully after treatment. Farmers noted that despite complete damage of leaves, including flag leaf by the leaf roller, panicles of those exotic cultivars emerged and fills grain using nutrient reserved in the stems. On the other hand, farmers reported that erect leaves of the cultivars facilitated to pass air and temperature through the fields so that infestation of BPH was low except in Swarna5 because of its wider leaves and more vegetative growth. Therefore, despite sensitivity of those cultivars to some pests, and level of infestation exceeded economic threshold level, their performance was not affected much. Farmers informed that level of susceptibility to pest of exotic varieties was not same among them. For instance, Mamun Swarna and Swarna5 are less prone to common diseases (sheath blight and sheath rot) than even Guti Swarna and BRRI varieties. However, Mamun Swarna is susceptible to false smut but its proneness to false smut is not as severe as BRRI dhan49. On the other hand, despite treatment, performance of BRRI varieties, in particular BR11 considerably affected because of insects (BPH, gall midge, nematode, caterpillar, mealy bug and stem borer) and diseases (sheath blight, sheath rot, tungro, ufra and false smut) infestation (Table 7).

Thirdly, farmers said that exotic cultivars having higher ability to absorb shock; in particular, they could recover from re- transplanting stress so quickly. For example, Guti Swarna gets adapted within 3-4 days of re-transplanting while it takes over a weak for other varieties. Besides, despite taller plant height the cultivars are less or not prone to lodging, even if unexpected rain and storm are occurred at reproductive stage, except Mamun Swarna, which is somewhat lodging prone if transplanted in low laying areas. Expert panel members were fully agreed with farmers' observations (Table 7).

Furthermore, respondents mentioned that flexibility in planting dates, agronomic management and suitability for cultivating in different topography areas (e.g., high, medium and low land) were crucial drivers of largescale adoption of exotic cultivars in survey locations. Firstly, the cultivars give consistent yield across different planting dates (early, optimum, delayed and extreme delayed e.g., 23rd week of September). Nonetheless, farmers reported that yield of BR11, BRRI dhan 49 and BRRI dhan52 largely decreased under both the early and delayed transplanting dates. It can be noted that early planting crop of BRRI varieties have severe pest infestation because of excess vegetative growth while delayed transplanting crops of BRRI varieties is affected by cold, consequently decrease yield. Secondly, exotic cultivars are suitable for cultivating in different topography areas (high, medium and low land) without much compensation in yields except Swarna5, which is not so suitable for high land with no opportunity for supplementary irrigation. It addition, Guti Swarna gives substantially higher yield than the other varieties in low laying areas. In contrary, BR11 and BRRI dhan49 is only compatible for medium high land, and BRRI dhan51 and BRRI dhan52 are suitable for planting in medium low land. Thirdly, exotic cultivars perform consistently despite poor agronomic practice such as less fertilizer and pesticides application, older seedling and no weeding and supplementary irrigation application despite drought at reproductive stage. However, performance of BRRI varieties substantially varied between poor and better agronomic practice particularly their performance is highly 
sensitive to fertilizer dose and its application time, seedling age and supplementary irrigation (Table 7).

Besides, farmers in group discussion said that despite longer growth duration the most dominant exogenous variety, Guti Swarna was not only suitable for three cropsbased systems but also compatible for planting even the early planting local variety potatoes. It is due to the photoperiod insensitive rice cultivar is matured for harvesting within the optimum planting time (before mid-November) of DS crops (potatoes, maize and garlic) if re-transplanted i.e., double transplanted 45-50 day-old seedling by mid-August. Moreover, its field duration is about 7-10 days shorter than BR11 and BRRI dhan51 and BRRI dhan52 so that farmers can plant dry season crops on time. Additionally, Swarna5 is not only compatible for three crops-based systems but also possible to harvest four crops as its life cycle is 20-25 days than Guti Swarna and 30-35 days shorter than BR11 and BRRI dhan51 and BRRI dhan52. In this respect, farmers' in the group discussion said that exotic varieties to enhance system productivity which motivates them to adopt those varieties (Table 7).

Moreover, key informants mentioned that the exotic cultivars were highly suitable for double transplanting which was also an important driver for adoption of those varieties in the extreme weather events (drought and flood prone) of northwest ecosystem. It can be noted that firstly double transplanting is an adaptation option to reduce field duration of the rice crop for facilitating optimum planting of DS crops. Secondly, it is a mechanism for stress management of cultivating rice in fields, which are not suitable for planting rice until extremely delayed planting date because of stagnant water or cultivation of early wet season rice. In addition, double transplanting has some obvious advantages including less seed requirement (only 12-15 $\mathrm{kg} / \mathrm{ha}$ ), pest infestation as well as higher yield (15-20\%) (Table 7).

Furthermore, respondents in group discussion reported that homogeneous plant height, dark green colour leaves until maturity, ability to emerge panicle really quickly (within 5-7 days) throughout the fields at a time and golden grain colour of exotic cultivars were also important drivers for large scale adoption of the cultivars. In other words, overall physiological appearance of the rice crops throughout the life cycle is really impressive and enchanting to look at, which plays positive roles for dissemination of the variety.

Finally, some respondents said that the variety was less fertilizer responsive (only one top dress of urea) due to dark green leaves, higher number of effective tillers, long panicle with mostly filled grain (e.g., less or no sterility), higher milling outturn than that of other varieties including BRRI developed new ones were the drivers of adoption of exotic variety. Besides, taller plant height with finer straw which is a preferred feed to cattle except Mamun Swarna that has a bit rough straw, as well as availability of seed at household and less seed intensive (1-2 seedling per hill) are also driver of adoption of those cultivars (Table 7).

\section{Economic drivers of adoption}

Farmers in group discussion said that despite price of exotic cultivars such as Guti Swarna and Mamun Swarna was slightly lower (BDT 750-1,500/ton) than Swarna5 and BRRI dhan49. However, their grain (0.75 to 1.25 ton/ha) and straw yield was higher than locally available BRRI varieties, consequently give higher return. These are the key criteria for large-scale adoption of the cultivars. Moreover, key informants reported that demand of paddy of exotic cultivars was high in local market. In part it was because of higher milling outturn and higher demand of husked rice of short bold grain (Guti Swarna) and bold grain (Mamun Swarna) rice at procurement centre. It was also because of adequate supply of paddy at local markets to meet up the requirement for operating an automatic rice mill.

On the other hand, demand of husked rice of medium slender grain of Swarna5 is also higher because it is one of the most 
preferred grains to consumers at market. Farmers said that on average, $70-85 \%$ of total farm produce of Guti Swarna and Swarna5, and $97-99 \%$ of total farm produce of coarse grain Mamun Swarna were marketable surplus. Thus, ensured market demand is also an important consideration for widespread adoption of the exotic cultivars (Table 7).

Furthermore, majority of respondents said that exotic cultivars were economically more viable (more profitable and less risky) due to less fluctuation in yield and price across seasons. Therefore, it is less likely to give negative return of those cultivars despite seasonal weather variation (less or heavy rain, floods, heat, dew and cold). Additionally, some farmers in group discussion claimed that exotic cultivars facilitated not only to enhance intensity of land use but also increased farm income through increasing total system productivity. This economic performance is also an important driver of adoption of the cultivars (Table 7 and Fig. 4).

\section{Social driver of adoption}

Cooked rice is not only tested good to eat but also leftover rice remains fresh for eating even in the following days. Therefore, most households (65-75\%) in Pirganj and some households (25-35\%) in Khanshama use Guti Swarna for family consumption for 5-7 months. On the other hand, most households (65-70\%) in Khanshama and some households (25-35\%) in Pirjanj use Swarna5 for family for 5-7 months. Mamun Swarna is mainly cultivated for commercial purpose as rice of the coarse grain not tasted good to eat.

Additionally, higher chance of reaping expected yield (4.5 -5.5 $\mathrm{tha}^{-1}$ ) across seasons as well as good yield of the cultivars even under worst seasonal conditions (i.e., not less than 3.9 $\mathrm{t} \mathrm{ha}^{-1}$ ) boost up their confidence regarding performance of the variety. Furthermore, farmers' have no worries regarding uncertainty of emerging panicle even though prevails severe moisture stress at the beginning of winter. Finally, shorter growth duration variety, such as Mamun Swarna and even the early transplanted longer growth duration varieties, for instance Guti Swarna and Swarna5 are also matured for harvesting at food and feed scarce period. Therefore, they get higher price for grain and straw at harvesting season and allow farmers an adequate turn-around time for land preparation for establishing dry season crops on time (Table 7).

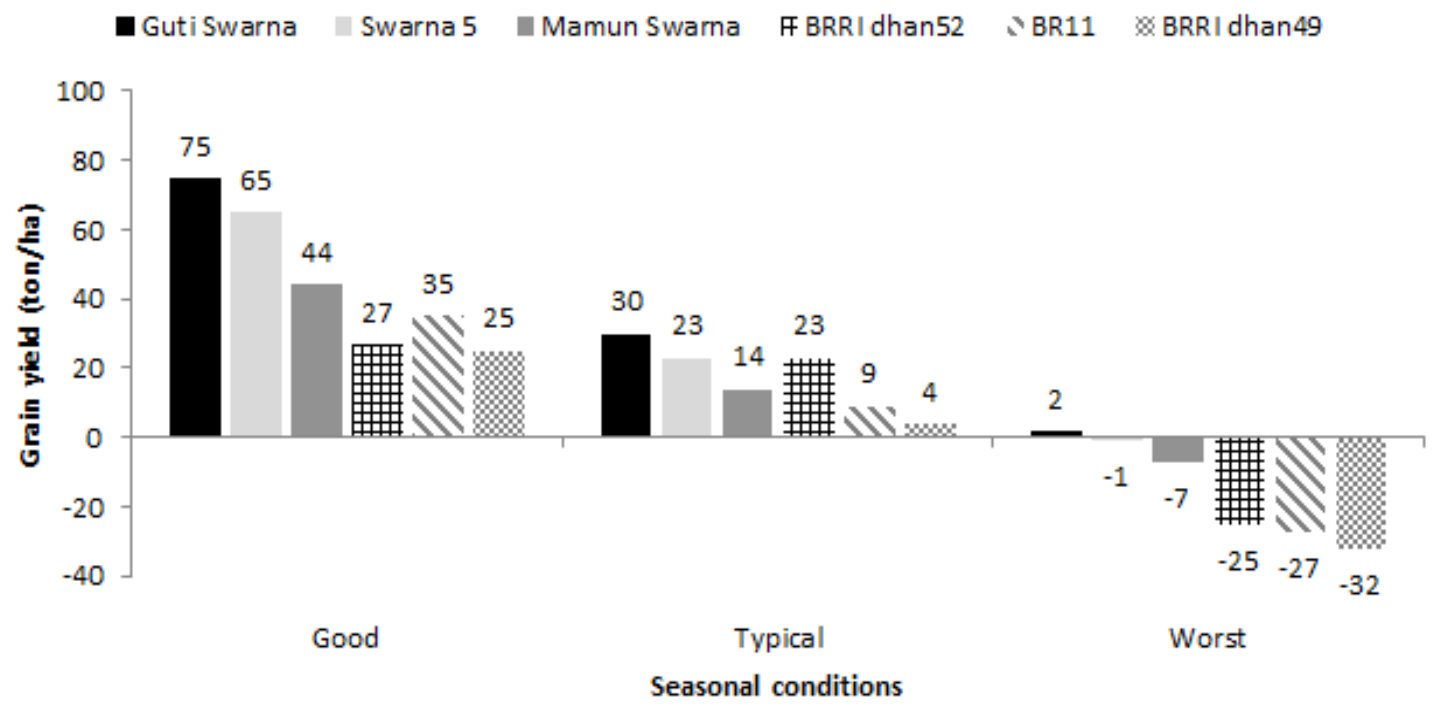

Fig. 4. Net income from wet season rice cultivars under different seasonal conditions in study locations. 
Table 7. Adoption drivers of exotic cultivars in wet season in Pirganj, Rangpur and Khanshama, Dinajpur.

Adoption drivers of exotic cultivars (Guti Swaran, Swarna5 and Mamum Swarna)

Agronomic driver

\begin{tabular}{|c|c|c|}
\hline Agronomic driver & & \\
\hline Consistent yield despite variation in seasonal weather and agronomic practices & 100 & 100 \\
\hline $\begin{array}{l}\text { Higher adaptive capacity to shocks and abiotic stress (floods, cold and droughts) except } \\
\text { Swarna5 which is somewhat prone to moisture stress }\end{array}$ & 100 & 100 \\
\hline Higher grain and straw yield than most other available varieties & 85 & 68 \\
\hline $\begin{array}{l}\text { Compatible for three crops-based systems, but Guti Swarna and Swarna5 are needed to } \\
\text { transplant early for sowing DS crops on time }\end{array}$ & 78 & 65 \\
\hline $\begin{array}{l}\text { Not only the cultivars are able to recover from major biotic stress (sheath blight and sheath } \\
\text { rot) but also, they are less prone to BPH, caterpillar and stem borer }\end{array}$ & 72 & 84 \\
\hline Quickly emerge panicle throughout the fields at a time & 100 & 100 \\
\hline $\begin{array}{l}\text { Highly suitable for double transplanting which is an important adaptation strategy of farm } \\
\text { households to climate change }\end{array}$ & 88 & 92 \\
\hline $\begin{array}{l}\text { Consistent performance under early, optimum, delay and even under extreme delay ( } 2-3^{\text {rd }} \\
\text { week of September) planting dates }\end{array}$ & 92 & 84 \\
\hline $\begin{array}{l}\text { Suitable for cultivating in different topography areas (high, medium and low land) without } \\
\text { much compensations of yield }\end{array}$ & 62 & 71 \\
\hline Less or no lodging, even if occur rain and storm at reproductive stage & 96 & 88 \\
\hline $\begin{array}{l}\text { Higher number of effective tillers and long panicle with mostly filled grain than that of } \\
\text { other varieties including BRRI cultivars }\end{array}$ & 76 & 68 \\
\hline Physiological appearance of the rice crops is impressive and enchanting & 100 & 100 \\
\hline Require less fertilizer (one top dress of N) and seed, seed is available at home & 100 & 100 \\
\hline Higher grain weight and more milling outturn than other varieties & 100 & 100 \\
\hline \multicolumn{3}{|l|}{ Economic driver } \\
\hline Profitable due to higher grain and straw yield, and good market price & 100 & 100 \\
\hline Higher demand of paddy at local market & 100 & 100 \\
\hline $\begin{array}{l}\text { Commercial farm enterprise as marketable surplus (MS) of rice ranges between } 70-85 \% \text { of } \\
\text { total farm produce except Mamun Swarna (97-99\% of total is MS) }\end{array}$ & 72 & 96 \\
\hline Less risky due to low variability in yield and price across seasons & 100 & 92 \\
\hline \multicolumn{3}{|l|}{ Social driver } \\
\hline $\begin{array}{l}\text { Farmers have no worries regarding uncertainty of emerging panicle even though prevails } \\
\text { severe moisture stress and beginning of winter. }\end{array}$ & 100 & 100 \\
\hline $\begin{array}{l}\text { Farmers cultivate exotic cultivars because of highly likely to harvest expected yield (4.5-5.5 } \\
\text { t/ha) despite variation in seasonal weather }\end{array}$ & 100 & 100 \\
\hline $\begin{array}{l}\text { Farmers' have very high confidence regarding better performance even in worst seasonal } \\
\text { conditions (yield not less than } 3.9 \mathrm{t} / \mathrm{ha} \text { ) }\end{array}$ & 100 & 100 \\
\hline $\begin{array}{l}\text { Cooked rice is not only good to eat but also leftover rice remains fresh for eating even in } \\
\text { the following days except Mamun Swarna (not tested well) }\end{array}$ & 100 & 100 \\
\hline $\begin{array}{l}\text { Delicious to eat so that most farm households in Pirganj and some in Khanshama consume } \\
\text { Guti Swarna for 5-7 months and vice versa for Swarna5 }\end{array}$ & 100 & 72 \\
\hline Soft straw is a preferred feed of cattle except Mamun Swarna & 64 & 72 \\
\hline \multicolumn{3}{|l|}{ Environmental driver } \\
\hline Consistent yield in erratic rainfall pattern and in low rainfall in post monsoon months & 100 & 100 \\
\hline Consistent yield in excess dew even in the early November and commencing winter early & 100 & 100 \\
\hline Tolerant to abiotic and biotic stress & 92 & 88 \\
\hline
\end{tabular}

Respondent (\%)

Pirganj Khanshama

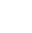


Environmental drivers of adoption

Farmers' perceived climate changes in erraticism of rainfall pattern and shifted delay of monsoon month causing unfavourable environment for nursery preparation and transplanting WS rice within optimum planting date. As a result, some modern varieties, such as BR11, BRRI dhan 49 and BRRI dhan52 perform poorly because of delayed transplanting. However, performance of exotic cultivars, for instance Guti Swarna, Swarna5 and Mamun Swarna are consistent despite transplanting until extreme delay transplanting dates. Moreover, increased heavy torrential rainfall events, decrease rainfall in post monsoon months and excess dew even in the early November, and commencing winter early also largely impact on yields of BRRI varieties (BR11, BRRI dhan49 and BRRI dhan52). Nevertheless, performance of exotic cultivars remains consistent despite such changes in environment. Thus, indigenous WS rice cultivars were replaced by the exotic cultivars (Table 7).

\section{Adoption drivers of less adopted cultivars in WS}

Table 8 presents adoption drivers of some minor varieties in study locations. Farmers in group discussion said that key adoption driver of Binadhan-7 and hybrid was shorter life cycle of those cultivars (25-30 days) than that of the other existing cultivars. It was noted that shorter growth duration of those cultivars allowed adequate turnaround time for land preparation in order to planting local variety potatoes and garlic early (late October to mid November), and other dry season crops on time. It can be noted that yield of local variety potatoes and onion not only decreased largely but also price of those crops decreased considerably because of transplanting delay. Therefore, the cultivars facilitate to enhance both system productivity and farm income. Furthermore, farmers reported that both of the cultivars matured for harvesting food and feed scarce period giving higher return because of higher straw price and good yield under optimum planting date. It increases system productivity and farm income. However, farmers in group discussion said that large scale dissemination of the cultivars is constrained by more susceptibility to abiotic (floods and moisture stress) and biotic (pest) stress than exotic inbred cultivars. It was observed in the fields that infestation of false smut was severe in some hybrid cultivars in particular Dhanigold. Moreover, performance of both the cultivars is not satisfactory under double transplanting and with seedling age over a month old. Nevertheless, sometimes farmers were unable to maintain seedling age less than a month due to erraticism of rainfall pattern as well as it is not possible to transplanting tenderly aged seedling in medium low to low land areas because of stagnant water. Furthermore, some of the key informants said that higher rate of unfilled grain in panicle, and infestation of ear cutter caterpillar and attack of rats and birds were also severe in the early maturing rice. Finally, cooked rice of coarse grain Binadhan-7 is soft, sticky and not tasted good to eat. On the other hand, although cooked rice of some hybrid is not much sticky but become so soft shortly and not tasted good to eat. Therefore, farmers reported that the cultivars such as hybrid and Binadhan-7 are mainly cultivated for commercial purpose (Table 8).

On the other hand, farmers in group discussion said that despite Ronjit is not suitable for three crops based system due to longer growth duration as well as unable to perform well under delayed planting date. However, farmers cultivated the variety not only because of its higher potentiality to give good grain yield (3.9-5.9 $\mathrm{t} \mathrm{ha}^{-1}$ ) as Swarna but also give good yield in the field with stagnant water and/or in low land. Additionally, key informant said that the variety was largely less susceptible to diseases and insects than that of the others. Moreover, most of the key informants reported that price of Ronjit (BDT 1.3-1.6 Tk/kg) was higher than that of dominant Guti Swarna and its demand in market was ensured. Furthermore, some households said that the medium slender grain was tasted good to eat, and was used for cooking scented rice in the festival as well. Finally, some respondents said that the variety was potential to higher straw yield and its soft stems were preferred feed to cattle. However, despite taller plant height, the variety is not lodging prone (Table 8). 
Table 8. Adoption Drivers of less adopted varieties in wet season in Pirganj, Rangpur and Khanshama, Dinajpur.

\begin{tabular}{|c|c|c|c|}
\hline \multirow[t]{2}{*}{ Variety } & & \multicolumn{2}{|c|}{ Respondent (\%) } \\
\hline & & Pirganj & Khanshama \\
\hline \multirow{15}{*}{ Binadhan-7 } & Adoption driver & & \\
\hline & $\begin{array}{l}\text { Shorter life cycle (90-95 days) so that matured for harvesting food and feed } \\
\text { scarce period, and compatible for three-crop based systems }\end{array}$ & 100 & 100 \\
\hline & Give good yield under optimum and even delay planting dates & 90 & 100 \\
\hline & Allows adequate turnaround time for land preparation for DS crops & 100 & 100 \\
\hline & Higher number of effective tillers & 70 & 70 \\
\hline & Profitable due to good yield and higher straw price & 70 & 80 \\
\hline & Increase system productivity and farm income & 75 & 80 \\
\hline & Adoption drawbacks & & \\
\hline & Give low yield for seedling age over a month & 100 & 100 \\
\hline & Lower grain and straw yield potential than Swarna & 100 & 100 \\
\hline & Emerge panicle gradually some after the others & 90 & 85 \\
\hline & Less number of effective tillers & 60 & 65 \\
\hline & Higher number of unfilled grains in the panicle & 75 & 60 \\
\hline & Cooked rice is not sticky but so soft and not tasted good to eat & 100 & 100 \\
\hline & High infestation of ear cutter caterpillar and attack of rats and birds & 60 & 70 \\
\hline \multirow{13}{*}{ Hybrid } & Adoption driver & & \\
\hline & Shorter growth duration than Guti Swarna (20-25 days) & 100 & 100 \\
\hline & Suitable for three crops-based systems including early planting DS crops & 100 & 100 \\
\hline & Matured for harvesting at food and feed scarce period & 80 & 85 \\
\hline & Medium slender grain & 60 & 55 \\
\hline & Profitable due to good yield and higher straw price & 70 & 75 \\
\hline & Shorter plant height and strong stem so that no lodging & 80 & 85 \\
\hline & Soft straw so that it is a preferred feed to cattle & 60 & 55 \\
\hline & Adoption drawbacks & & \\
\hline & Unable to perform well under double transplanting condition & 100 & 100 \\
\hline & Some give lower yield than Guti Swarna, and highly prone to sterility & 55 & 60 \\
\hline & Some are highly susceptible to pest including sheath blight and false smut & 40 & 35 \\
\hline & Cooked rice of coarse one is soft and sticky, so not tasted good to eat & 90 & 95 \\
\hline \multirow{12}{*}{ Ronjit } & Adoption driver & & \\
\hline & Higher grain yield potential (3.9-5.9 t/ha) as Swarna & - & 100 \\
\hline & Gives higher yield in early and optimum planting dates & - & 95 \\
\hline & $\begin{array}{l}\text { Higher demand and price (BDT 1.3-1.6/kg) than Swarna as the medium } \\
\text { slender grain is tasted good to eat and used for cooking scented rice }\end{array}$ & - & 90 \\
\hline & Less disease and pest susceptible & - & 80 \\
\hline & Perform well in the field with stagnant water in the low laying areas. & - & 100 \\
\hline & Higher milling outturn because of thin shell & - & 95 \\
\hline & Taller plant height but the stem is strong so that no lodging & - & 100 \\
\hline & Higher straw yield and its soft stems are preferred feed to cattle & - & 95 \\
\hline & Adoption drawbacks & - & \\
\hline & $\begin{array}{l}\text { Decreased yield in case of delay of planting while early planting one is } \\
\text { severely affected by rat }\end{array}$ & - & 100 \\
\hline & $\begin{array}{l}\text { Longer life cycle (one week) than Guti Swarna so that not suitable for three } \\
\text { crops-based system }\end{array}$ & - & 100 \\
\hline
\end{tabular}

Source: Field survey 2018. 


\section{Factors of decreasing or low adoption of BRRI varieties}

BR11. Farmers in group discussion said that BR11 was the most dominant variety covering over about $70-75 \%$ of total area of WS rice in both the study locations until 2000 mainly because it would perform better than that of the then available cultivars. Additionally, cooked rice of coarse grain was preferred food to farm families. However, key informants said that currently adoption of the variety plunged to bottom mainly because of the variety mostly unable to perform consistently under changed environment despite better management. Farmers said that performance of the variety substantially fluctuated because of variation in seasonal weather, land types and agronomic management (sowing dates, seedling age and fertilizer rates). In this respect, farmers in group discussion said that even under slightly delayed transplanting date, the variety was unable to produce panicles fully after commencing winter or falling dew at night despite supplementary irrigation application; consequently, gave low yield. Nevertheless, farmers are mostly forced to delay in transplanting WS rice in medium low land (only where the variety perform well under favourable condition and better management) due to shifted delay of monsoon and highly likely to affected by flood at transplanting and tillering stage of early transplanting crops in the area. Farmers in group discussion said that the variety was not suitable for three crops systems. It is due to the mild photoperiod sensitive long duration cultivar does not mature for harvesting within optimum planting date of DS crops despite early transplanting. Additionally, the variety was mostly unable to perform well in high to medium high land because of its higher proneness to moisture stress. Key informant said that, yield of BR11 considerably decreased due to seedling age over a month, and inadequate (more fertilizer intensive) or untimely application of fertilizer and double transplanting. In the contrary, available exotic cultivars (Guti Swaran and Swarna5) not only gives higher yield than that of BR11 under typical seasonal condition but also consistently performs better despite variation in weather and agronomic management (Table 9 and Fig. 3).

Furthermore, farmers in group discussion said that another vital reason of decreasing adoption of BR11 was that it was not only severely susceptible to insects $(\mathrm{BPH}$, gall midge, mealy bug, and stem borer) and diseases (sheath blight, sheath rot, tungro and ufra) but also mostly unable to recover from infestation of pest fully despite treatment, resulting from that largely decrease yield. This is also an important reason of decreasing the adoption of the variety. Besides, some respondents said that although tillering ability of the variety was high, while number of effective tillers was low and more unfiled grain in panicles. Finally, some key informants said that BR11 is economically less viable (less profitable and risky) because of its higher yield variability to small farm households stop cultivating the variety. Moreover, demand and price of the paddy rice at local market is low as most farm families do not prefer to eat rice of coarse grain variety (Table 9 and Fig. 4).

BRRI dhan33. Farmers in group discussion said that despite shorter growth duration, farmers stopped cultivating BRRI dhan33 as the cultivar not only gave lower yield than Binadhan-7 and hybrid but also, they did not prefer to consume coarse grain rice and its plants were highly susceptible to lodging (Table 9).

BRRI dhan49. Key informants reported that BRRI dhan49 is one of the most preferred cultivars to households for consumption, and the variety is potential to give good yield under better management and favourable weather. Additionally, price of the paddy is higher than even the Swarna5, and its life cycle is medium so that compatible for even the three crop-based systems. Furthermore, the cultivar is less or not susceptible to $\mathrm{BPH}$ and its straw is preferred feed to cattle. However, farmer's in-group discussion said that despite above mentioned positive criteria, adoption of the variety was low or decreasing. Firstly, because of its severe susceptibility to false 
smut as the disease affected both on yield and market price because of discolouration. Secondly, both grain and straw yield of the cultivar even under typical seasonal condition is not only lower than that of Swarna but also its performance largely varied across different seasonal conditions, land types and management (fertilizer dose and planting dates). Thirdly, the cultivar gave low yield in case of aged seedling and not even suitable for double transplanting because its panicles emerge within a short period of retransplanting, consequently providing low yield. Finally, the variety is highly susceptible to leaf roller and stem borer. Besides, despite applying supplementary irrigation, panicles of the cultivar do not emerge fully after beginning of winter. Overall, farmers said that highly uncertain performance under stress environment and severe susceptibility to false smut were the root cause of not being popular of the variety (Table 9).

BRRI dhan51. Key informant reported that BRRI dhan51 had some strong positive traits including tolerant to 10-12 days of flash flood submergence, strong stem, less susceptibility to pest, medium slender grain, tasted good to eat, higher market demand and suitability for double transplanting and to some extent cold tolerant. So, this variety is potential for large scale dissemination in the flood prone ecosystem in Bangladesh. However, adoption of the variety remains low, firstly because of most areas of the study locations are under three-crop-based systems; nonetheless, neither the long duration cultivars is compatible for three crops systems nor it is potential to perform better than available exotic cultivars (Swarna). In addition, respondents said that performance of cultivars unable to out weight Swarna even in the low to medium low areas because of its less tillering ability and lower number of effective tiller (Table 9).

BRRI dhan52. Farmers in group discussion reported that despite some positive traits for instance tolerance to 10-12 days flash flood submergence, strong stem and high milling outturn adoption of the variety is low in the area. It is due to firstly; the variety gives lower yield than exotic cultivars. Secondly, the yield of the variety highly fluctuates because of seasonal weather variation as like as BR11, BRRI dhan 49 and BRRI dhan52. Thirdly, the variety is highly susceptible to $\mathrm{BPH}$ and fungal diseases. Finally, demand of the paddy is low due to small lot of supply (Table 9).

BRRI dhan56 and BRRI dhan57. Farmers in group discussion reported that despite shorter growth duration and drought tolerance or escaping, adoption of those variety is low mainly because of availability other varieties higher yield potential short duration in particular hybrid (5.5-6.5 t/ha), Binadhan-7 and Swarna5 (4.9-5.9 t/ha). Moreover, BRRI dhan56 has bold grain so that market demand for the rice is low (Table 9).

\section{Performance of new BRRI varieties in demonstration plots}

Farmers and expert panel members have found some potentiality for diffusion of BRRI dhan66, BRRI dhan71 and BRRI dhan75 in wet season in Pirganj and Khanshama. It was due to BRRI dhan66 is potential to give higher grain and straw yield. Additionally, it is a medium long duration variety suitable for three-crop-based system. It is a medium bold grain cultivar, having good market demand, and the cultivars are to some extent stress (drought and no lodging) tolerant. Similarly, key informant said that BRRI dhan71 and BRRI dhan75 perform well i.e., gave higher grain (5.5-6.2 $\mathrm{t} \mathrm{ha}^{-1}$ ) and straw yield on trial plots in high and medium high land. Additionally, both are short duration so that (i) highly compatible for three crops-based systems and (ii) potential to escape moisture and cold stress. Furthermore, farmers in-group discussion anticipated that demand and price of the medium slender rice at local market will be high and cooked rice of the variety would be tasted good to eat. Finally, the variety is somewhat less susceptible to pest. However, small-scale infestation of false smut was common in the demonstration plots of both the cultivars (Table 10). 
Table 9. Adoption drivers and drawbacks of some BRRI cultivars in WS in Pirganj, Rangpur and Khanshama, Dinajpur.

\begin{tabular}{|c|c|c|c|}
\hline \multirow[t]{2}{*}{ Variety } & \multirow[t]{2}{*}{ Adoption driver and drawback } & \multicolumn{2}{|c|}{ Respondent (\%) } \\
\hline & & Pirganj & Khanshama \\
\hline \multirow{8}{*}{ BR11 } & \multicolumn{3}{|l|}{ Adoption driver } \\
\hline & Gives higher yield under favourable conditions and better management & 100 & 100 \\
\hline & Tasted good to eat & 100 & 100 \\
\hline & \multicolumn{3}{|l|}{ Drawback } \\
\hline & $\begin{array}{l}\text { Unable to produce panicle fully despite application of supplementary } \\
\text { irrigation if commence winter or fall dew at night }\end{array}$ & 100 & 100 \\
\hline & $\begin{array}{l}\text { Severely susceptible to insects (BPH, gall midge, mealy bug, ear cutter caterpillar } \\
\text { and stem borer) and diseases (sheath blight, sheath rot, tungro and ufra) }\end{array}$ & 100 & 100 \\
\hline & Poor performance under double transplanting & 90 & 95 \\
\hline & $\begin{array}{l}\text { Despite transplanting early, the mild photoperiod sensitive cultivar does not } \\
\text { mature for harvesting within optimum planting time of DS crops, } \\
\text { consequently decrease systems productivity }\end{array}$ & 75 & 80 \\
\hline \multirow{5}{*}{$\begin{array}{c}\text { BRRI } \\
\text { dhan33 }\end{array}$} & \multicolumn{3}{|l|}{ Adoption drivers } \\
\hline & Shorter growth duration & 90 & 95 \\
\hline & Drawback & & \\
\hline & Grain is bold & 100 & 100 \\
\hline & Highly lodging susceptible & 95 & 90 \\
\hline \multirow{12}{*}{$\begin{array}{c}\text { BRRI } \\
\text { dhan } 49\end{array}$} & \multicolumn{3}{|l|}{ Adoption driver } \\
\hline & $\begin{array}{l}\text { Potential to give good yield under better management and congenial } \\
\text { environment }\end{array}$ & 100 & 100 \\
\hline & Price is higher than the Swarna5 & 100 & 100 \\
\hline & Tasted good to eat & 90 & 90 \\
\hline & Compatible for three crops-based systems & 80 & 85 \\
\hline & Less or no susceptible to BPH & 90 & 84 \\
\hline & \multicolumn{3}{|l|}{ Drawback } \\
\hline & Severely false smut susceptible. & 100 & 100 \\
\hline & Demand of false smut affected paddy is low due to discolouration & 90 & 85 \\
\hline & Poor recoverability from stresses (floods, droughts and cold) & 80 & 85 \\
\hline & Poor performance in case of aged seedling and double transplanting & & \\
\hline & Susceptible to insects (leaf roller and stem borer) & 85 & 90 \\
\hline \multirow{8}{*}{$\begin{array}{l}\text { BRRI } \\
\text { dhan51 }\end{array}$} & \multicolumn{3}{|l|}{ Adoption driver } \\
\hline & Tolerant to 10-12 days of flash flood submergence & 100 & 100 \\
\hline & Strong stem and less susceptibility to pest & 80 & 75 \\
\hline & Medium slender grain and tasted good to eat & 90 & 85 \\
\hline & Suitability for double transplanting and some extent tolerant to cold & 80 & 85 \\
\hline & Drawback & & \\
\hline & Incompatible for three crops-based system due to longer life cycle & 70 & 60 \\
\hline & Less tillering ability in anaerobic condition & 75 & 70 \\
\hline \multirow{6}{*}{$\begin{array}{c}\text { BRRI } \\
\text { dhan52 }\end{array}$} & \multicolumn{3}{|l|}{ Adoption driver } \\
\hline & Tolerance to 10-12 days flash flood submergence & 80 & 85 \\
\hline & Strong stem and higher milling outturn & 85 & 88 \\
\hline & \multicolumn{3}{|l|}{ Drawback } \\
\hline & Susceptible to stresses (drought, cold and dew) at reproductive stage & 75 & 72 \\
\hline & Susceptible to BPH and fungal disease & 70 & 65 \\
\hline
\end{tabular}

Source: Field Survey 2018. 
Table 10. Perception of key informants about potentiality of newly released BRRI varieties based on performance of the cultivars in demonstration in Pirganj, Rangpur and Khanshama, Dinajpur.

Adoption driver

\begin{tabular}{|c|c|c|}
\hline \multirow{7}{*}{$\begin{array}{c}\text { BRRI } \\
\text { dhan66 }\end{array}$} & $\checkmark$ & Higher grain and straw yield potential \\
\hline & $\checkmark$ & Medium growth duration \\
\hline & $\checkmark$ & Medium bold grain \\
\hline & $\checkmark$ & Wider leaves \\
\hline & $\checkmark$ & No lodging despite taller plant height \\
\hline & $\checkmark$ & Higher straw yield \\
\hline & $\checkmark$ & Somewhat tolerant to drought \\
\hline \multirow{5}{*}{$\begin{array}{c}\text { BRRI } \\
\text { dhan71 }\end{array}$} & $\checkmark$ & Gives good yield (5.5-6.0 t/ha) on trial plots in high and medium high land \\
\hline & $\checkmark$ & Taller plant height, gives higher straw yield, less lodging prone \\
\hline & $\begin{array}{l}\checkmark \\
\text { pot }\end{array}$ & $\begin{array}{l}\text { Shorter growth duration so that (i) highly compatible for three-crop-based systems and (ii) } \\
\text { to escape moisture and cold stress }\end{array}$ \\
\hline & $\checkmark$ & Medium slender grain, good to eat and higher market demand \\
\hline & $\checkmark$ & Less pest infestation, but some false smut infestation was observed \\
\hline \multirow{4}{*}{$\begin{array}{c}\text { BRRI } \\
\text { dhan75 }\end{array}$} & $\checkmark$ & Good yield (5.5-6.2 $\mathrm{t} / \mathrm{ha})$ on trial plots in high and medium high land \\
\hline & \multicolumn{2}{|r|}{ potential to escape moisture and cold stress } \\
\hline & $\checkmark$ & Demand and price might be higher of the slender and mild aroma grain \\
\hline & $\checkmark$ & Less pest infestation, but some false smut infestation was observed \\
\hline
\end{tabular}

Source: Field survey 2018

\section{Dream variety}

Farmers were asked to report biophysical and economic traits of their dream variety for WS. Thereafter, they were asked to rank the traits based on importance from 1-7 scale. Finally, they were asked to anticipate how much area could be covered by the variety in the study locations. Accordingly, key informants classified their dream varieties into two based on major cropping systems. Table 9 presents traits and their rank of dream variety for threecrop-based cropping systems for high to medium high lands. Dream cultivar with shorter field duration (110-115 days) so that allows farmers to establish DS crops early or within optimum planting date, and potential to give higher grain (6.5-6.9 t/ha) and straw yield with better quality, were ranked as first and second important traits, reported by $100 \%$ of total respondents. Key insight of most preferred traits (first and second) of dream cultivar clearly expressed that farmers do not only expect better harvest (grain and straw) from WS rice but also, they are dreaming a variety which would be potential for intensification of cropping system and enhancing total system productivity. It indicates that farmers expect better harvest from WS rice as well as fully conscious to reap full benefit of cultivating crops in the following seasons. Furthermore, farmers expect quality rice (i.e., medium slender grain with high amylose contains and cooked rice is good to eat) in order to ensure demand and higher price as well as for household consumption. It indicates that rice cultivation is not at all a subsistence enterprise; rather it has become a commercial enterprise. On the other hand, farmers also aware of yield and quality of straw (soft so that cattle prefer to eat) as rearing cattle is an important 
component of farming systems in the study locations (Table 11).

Multi stress tolerant and to some extent flexibility in agronomic practices to alleviate likelihood of seasonal yield fluctuation despite variation in seasonal weather (heat, extreme weather events and pest infestation) and agronomic management (planting dates, fertilizers dose and time of application), ranked as third and fourth most important traits, reported by $74-83 \%$ of total respondents. It indicates that farmers expect a consistent performance despite biotic and abiotic stress and variation in management (delay or early transplanting, higher or lower fertilizers dose with untimely application). Finally, rest of traits (5-7) of dream cultivar is mostly related to anatomy of the rice plant, reported by 48 $58 \%$ of total respondents. It is expected that the cultivars should be medium tall plant height having strong stem so that no lodging despite rain in post monsoon months. Moreover, higher number of effective tillers (15-18) with homogenous growth and dark green colour erect leaves (less bushy) so that air and sunshine could pass through the fields, consequently less infested by insects and diseases. In addition, panicles of the grain should emerge so quickly at a time despite stress and long panicle with glossy golden colour grain having no sterility and higher milling outturn. The key insight of the traits of the dream variety is that farmers expected sustainable biophysical, economic and social performance of total cropping systems. Framers and extension personnel unanimously agreed that diffusion of the dream cultivars might be on average $50-60 \%$ of total area of WS rice (Table 11).

Table 12 presents traits and their rank of dream variety of wet season rice for two crops systems in medium low to low lands. It was observed (Tables 11 and 12) that phenotypes of both the cultivars for two crops system and three crops system mostly consistent except ranking in first and second most important traits. Higher yield potential and medium fields duration are ranked as first and second most important traits, reported by $100 \%$ of respondents. It is mainly because of farmers expects higher yield at the cost of allocating additional time (medium field duration) and excepting some extent poorer quality (medium coarse grain) from the two crops systems in order to equalize total productivity of both three and two crops systems. Farmers in group discussion reported that bulk supply of medium bold grain rice will be ensured its demand and fair price as medium bold grain rice has higher demand at procurement center so that large traders and millers purchase the rice at better price from even local market.

Table 11. Phenotype of dream variety of wet season for three-crop system in high to medium high lands.

\begin{tabular}{|c|c|c|c|}
\hline Trait & Respondent (\%) & Rank & $\begin{array}{l}\text { Potential } \\
\text { area }(\%)\end{array}$ \\
\hline Shorter field duration (110-115) & 100 & 1 & \multirow{5}{*}{$\begin{array}{c}50-60 \% \text { of } \\
\text { total area of } \\
\text { WS rice }\end{array}$} \\
\hline $\begin{array}{l}\text { Higher grain (6.5-6.9 ton/ha) and straw yield potential with better } \\
\text { quality (medium slender grain, high amylose and tasted good to eat) }\end{array}$ & 100 & 2 & \\
\hline Stable to perform under variable stresses & 83 & 3 & \\
\hline $\begin{array}{l}\text { To some extent flexible to agronomic management i.e., consistent yield } \\
\text { despite variation in planting dates, fertilizer dose and application time }\end{array}$ & 74 & 4 & \\
\hline $\begin{array}{l}\text { Medium plant height with strong stem so that no lodging despite rain } \\
\text { in the post monsoon months and emerge panicle quickly at a time }\end{array}$ & 58 & 5 & \\
\hline Long panicle with glossy golden colour grain and no sterility & 52 & 6 & \\
\hline $\begin{array}{l}\text { Homogenous plant height, higher effective tillers (15-18) and dark } \\
\text { green colour erect leaves (less bushy) }\end{array}$ & 48 & 7 & \\
\hline
\end{tabular}


Table 12. Phenotype of dream variety of wet season for two crops system in medium low to low lands.

\begin{tabular}{|c|c|c|c|}
\hline Trait & Respondent (\%) & Rank & $\begin{array}{c}\text { Potential } \\
\text { area }(\%)\end{array}$ \\
\hline $\begin{array}{l}\text { Higher grain (6.9-7.9 ton/ha) and straw yield potential with better quality } \\
\text { (medium coarse grain, high amylose and tasted good to eat) }\end{array}$ & 100 & 1 & \\
\hline Medium field duration (120-125) & 100 & 2 & \multirow{6}{*}{$\begin{array}{c}40-50 \% \text { of } \\
\text { total area } \\
\text { of WS } \\
\text { rice. }\end{array}$} \\
\hline $\begin{array}{l}\text { Multi stress tolerant (pest, floods, drought and cold) i.e., potential to } \\
\text { perform consistently despite variation in seasonal weather }\end{array}$ & & 3 & \\
\hline $\begin{array}{l}\text { To some extent flexible to agronomic management i.e., consistent yield } \\
\text { despite variation in planting dates, fertilizer dose and application time }\end{array}$ & 70 & 4 & \\
\hline $\begin{array}{l}\text { Medium plant height with strong stem so that no lodging despite rain in } \\
\text { the post monsoon months and emerge panicle quickly at a time }\end{array}$ & 58 & 5 & \\
\hline Long panicle with glossy golden colour grain and no sterility & 52 & 6 & \\
\hline $\begin{array}{l}\text { Homogenous plant height, higher effective tillers (15-18) and dark green } \\
\text { colour erect leaves (less bushy) }\end{array}$ & 48 & 7 & \\
\hline
\end{tabular}

Source: Field survey 2018

\section{Model for rapid diffusion}

Key informants including famers and extension personnel said that performance of a variety in terms of yield, growth duration, biotic and abiotic stress tolerance, market demand and eating quality was the prime driver that profoundly influence adoption decision of a variety. Besides, availability of seed of the better performed variety at local market plays a crucial role in the process of dissemination of the variety. However, farmers in the group discussion reported that performance of some newly released varieties failed to meet up the farmers' expectation. On the other hand, although some varieties have performed well in the demonstration plots and farmers are willing to cultivate these; nevertheless, seed of the varieties at local level is scarce. Farmers and extension personnel said that main reason of unavailability of seed of the newly released variety at local level was the national level seed producing organization namely BADC as well as the most private seed traders mainly produced seed for most popular varieties in use to avoid risk. In this regards, BADC and private seed traders noted that lack of information regarding the location specific demand of the rice varieties for different seasons in particular demand for the newly released varieties is an important factor of continuing production of the most dominant varieties. It is also the case that BADC has limited capacity to fulfil the huge demand of rice seed for the whole country. In this regards, BADC personnel and private seed traders said that insuring availability of breeder seeds and information regarding actual variety specific demand for seed were very important to enhance adoption of the newly released potential rice varieties at farmers' fields.

Moreover, all the expert personnel (BADC, private traders, extension personnel) strongly recommended that commercial cultivation of seed by the progressing farmers could be a crucial strategy to ensure mass farmers access to quality seed to increase adoption of potential varieties to enhance production of rice for meeting the growing demand of increased population. So, identification of interested farmers for developing private seed entrepreneurship and providing training to them on seed production and storage is essential. On the other hand, expert personnel suggested that large scale demonstration of some potential variety for the selected regions instead of providing small scale trials in the whole country could create impacts in the process of diffusion of the varieties. Based on the discussion with the expert personnel and key informant's farmers following strategies could be effective to reduce adaptation lag of the newly released potential rice varieties (Fig. 5):

- Select higher yield potential and stress tolerant cultivars which are medium slender grain and compatible for existing two or three-crop based cropping pattern. 
- Large scale demonstration on potential varieties in the selected regions instead of small scale demonstration on all the potential varieties in the whole country.

- Arrange field-days with participation of farmers of the entire communities along with the private seed traders to show the performance and explain them about the potentiality of the varieties.

- Identify farmers and private traders from the field day participant who are interested to produce seed of the varieties commercially.

- Provide training on seed to seed rice production package and storage of the seeds at farmers' place for marketing.

- Produce seed for 2-3 years through on farm trial in the selected trained farmers' fields could be more effective to enhance expertise of farm households which might be highly effective to develop private seed entrepreneurship at farm level.

- Develop of region and season specific rice production manual and wide spread circulation to the extension personnel and farmers.

- Develop and disseminate of modern rice production technology based applications
(APPs) widely to farmers and extension personnel.

- Develop leaflet on traits of newly BRRI released varieties and its wide scale circulation to farmers, extension personnel and traders to create awareness regarding the varieties, which could enhance market demand.

Figure 5 shows that a slight modification in the traditional seed network could make the seed available of potential new cultivars at local levels. First, DAE will popularize the newly released variety to the farmers by its demonstration process. After that, DAE will estimate upazila wise demand of seed for the newly released potential rice cultivars. They will inform the requirement to BADC well ahead of commencing seed production programme for the following seasons with an assurance that DAE will make arrangement for marketing the seed through local level retailers. In this system, BADC and other seed traders will minimize market risk of multiplying new rice varieties. Besides, the farmers will get quality seed of the new varieties with reasonable market price.

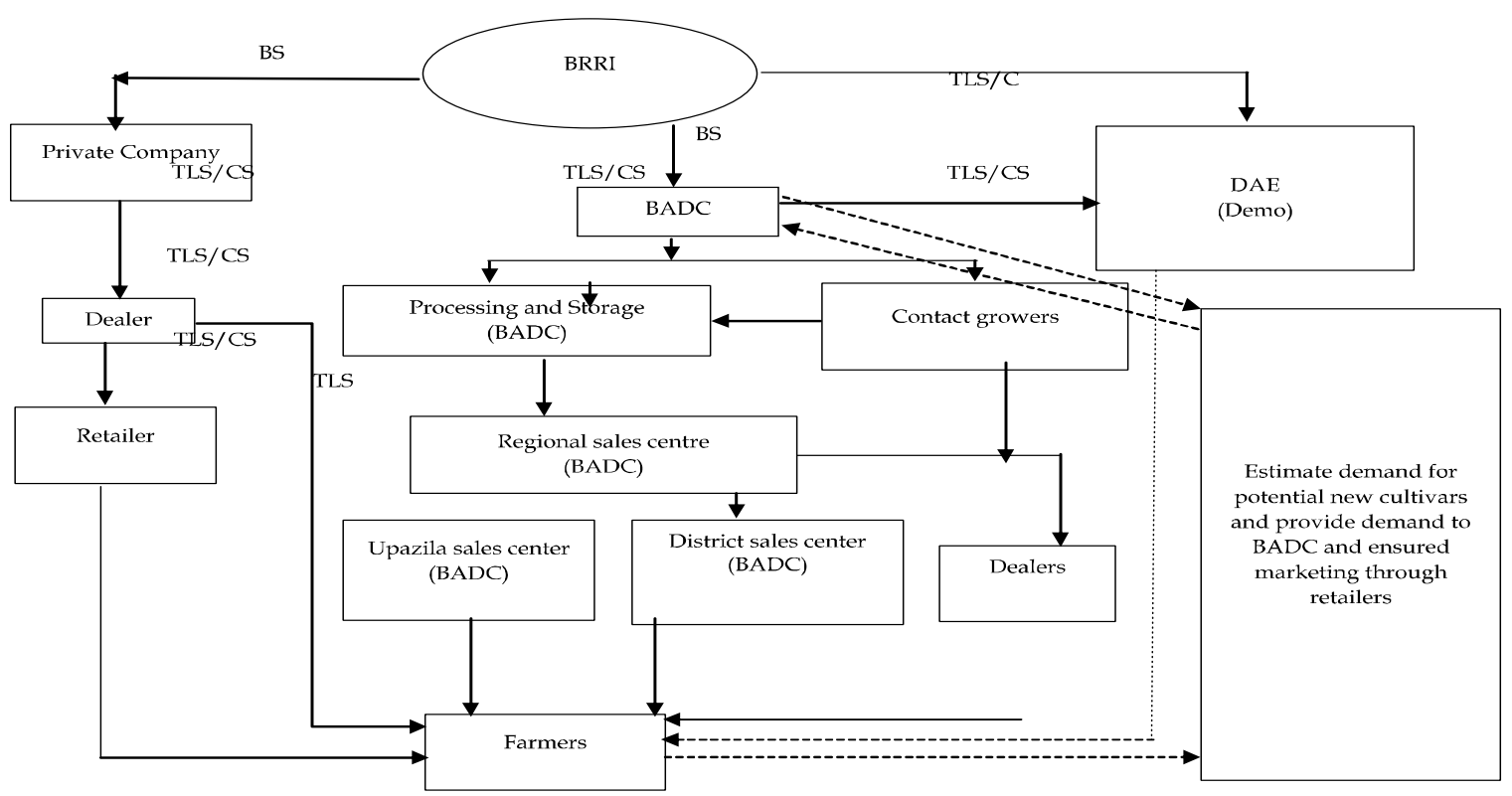

Fig. 5. Proposed modification in the existing seed network in Bangladesh. Note: BS= Breeder seed, TLS= Truthfully leveled seed, CS= Certified seed 


\section{Proposed dissemination model}

This study proposes a new seed dissemination model for rapid distribution of the newly released rice cultivars to the farm level. The model is based on concept of Seed Village in the farm level. BRRI and DAE will work collaboratively to form the seed village with their resources (Fig. 6). The DAE will go for large scale dissemination of the newly released varieties in the concerning regions. After the large scale demonstration, farmers' field day will be conducted in the farm level. The objective of the farmers' field day is to select the progressive farmers and seed traders who are willing to produce seed for this new variety.
The selected progressive farmers and traders will be provided seed to seed rice production training, support, rice production manual as well as hands on quality seed production support for producing efficient seed producer. The personnel in seed well age will be wel awer of the local centers seed production and dissemination sceneries to meet the local demand within the villages. The trained seed growers and seed traders will supply quality seed to the local seed traders and farmers. The entire system will be monitored by Seed Certification Agency (SCA), DAE and BRRI for ensuring seed quality, timely dissemination and adequate price to run the 'Seed Village' smoothly.

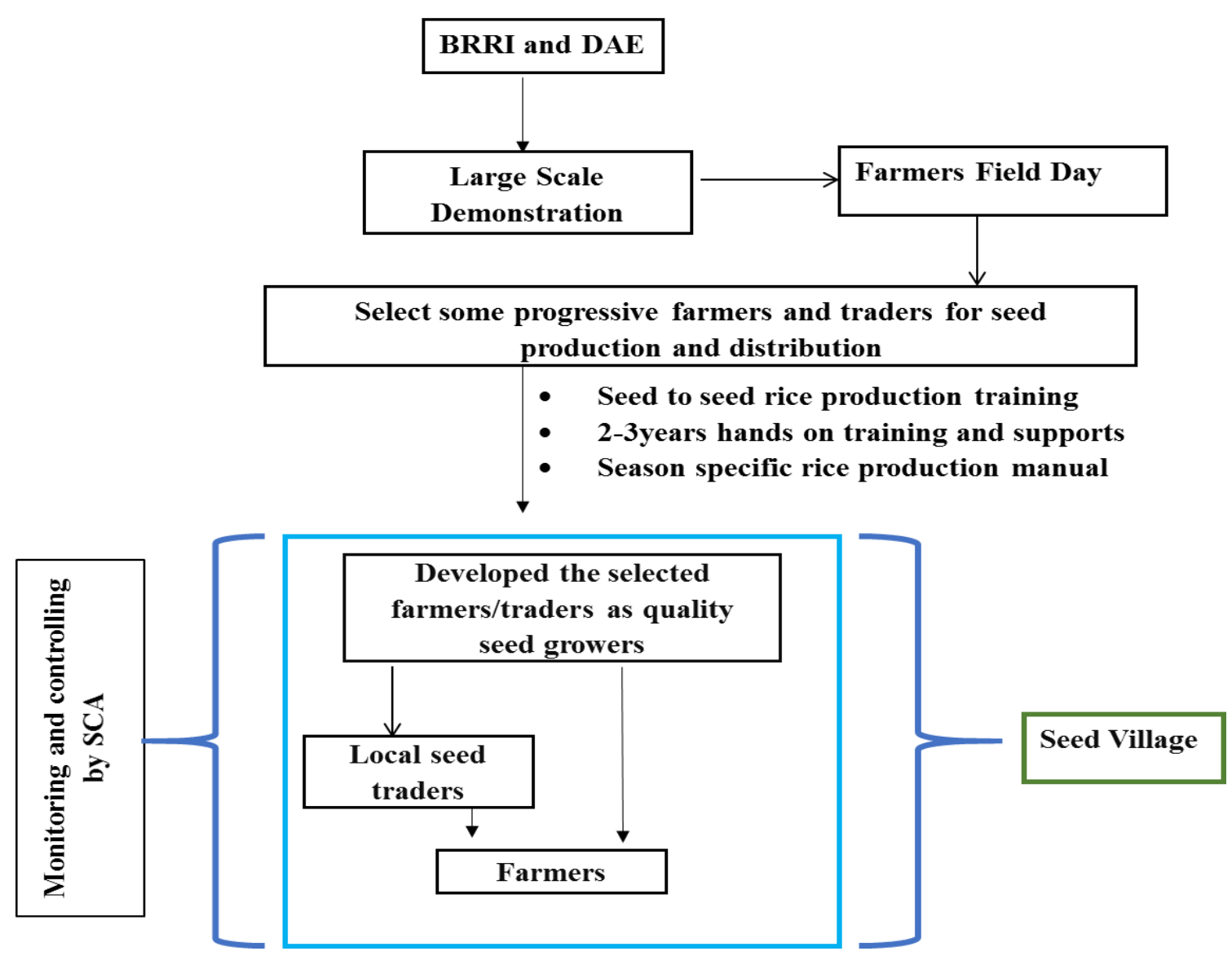

Fig. 6. Proposed model for rapid disseminations of rice cultivars to farmers fields. 


\section{CONCLUSION}

Rain-fed rice is one of the worst victims of biotic and abiotic stresses in north-west drought prone ecosystem in Bangladesh. Farmers' perceived changes in climate including rising temperature, shifted delay of rainfall, erraticism of rainfall pattern and duration of winter and gravity of cold. Therefore, farmers have introduced some planned and local adaptation strategies including changes in rice cultivars, double transplanting, application of supplementary irrigation and shifting early and/or delay transplanting dates. Farmers have adopted both the indigenous and exotic wet season (WS) rice cultivars to reduce unexpected yield loss due to abiotic and biotic stresses. Diffusion status of exotic cultivars was ranged between $76-85 \%$ of total WS rice area in the study locations. The drivers of widespread diffusion of exotic cultivars included the followings: Firstly, stability in performance of the cultivars despite variation in seasonal weather conditions, agronomic management (seedling age, planting dates and fertilizer dose and application time) and land types (high medium and low land). Secondly, higher compatibility to fit into local cropping systems, and ability to recover from biotic and abiotic stresses. Thirdly, higher potentialities to perform under double transplanting technique, and steady performance despite extreme weather events (floods, droughts and cold). Finally, ability to emerge panicle really quickly (within seven days) despite moisture stress, dew, cold and even severe infestation pest, and ultimately unique appearance of rice crops across fields. In fact, exotic cultivars outweigh indigenous cultivars in terms of performance, market demand, and stress tolerance ability. Overall, sustainable performance of exotic cultivars under changed environment has boosted up confidence level of farm households to peak which is pivotal for booming diffusion of the cultivars in WS in the locations. However, farmers are looking for further better performing cultivars for replacing exotic cultivars due mainly to their higher susceptibility to pest, and taste of cooked rice. Thus, farmers are dreaming of potential cultivars for fitting into two and three-crop-based systems in the areas. The phenotype of dream cultivar for three-crop systems included shorter field duration (110115 days) with higher grain (6.5-6.9 $\left.\mathrm{t} \mathrm{ha}^{-1}\right)$ and straw yield, multi stress tolerance quality rice (medium slender grain with high amylose). However, farmers expect further higher yield potential (6.9-7.9 $\left.\mathrm{t} \mathrm{ha}^{-1}\right)$ cultivars for two-crop system at the cost of allocating additional time (field duration, 120-125 days) along with other phenotype as dream cultivar for two crops systems. It can be noted that performance of indigenous cultivars BRRI dhan71 and BRRI dhan75 in demonstration plot is highly consistent with phenotype of three-crop systems. However, seed of the potential cultivars neither is currently available at local level nor the DAE has enough capacity to make the seed available to meet demand for local farmers in the near future. Thus, developing commercial seed producers through providing training and other supports to the selective progressive farmers for 3-4 years could be a highly effective model for rapid diffusion of the potential new cultivars at farm level.

\section{REFERENCES}

BBS. 2017. Preliminary Report on Household Income and Expenditure Survey 2016, Bangladesh Bureau of Statistics (BBS), Statistics and Information Division, Ministry of Planning, Government of the People's Republic of Bangladesh.

Hussain, S G. 2011. Assessing Impacts of Climate Change on Cereal Production and Food Security in Bangladesh. In: R Lal, A H M M Rahman, M V K Sivakumar, K R Islam, and S M A Faiz (eds.). Climate Change and Food Security in South Asia. pp. 459-476). Netherlands: Springer.

Kabir, M J, R Cramb, M Alauddin and C Roth. 2016. Farming adaptation to environmental change in 
coastal Bangladesh: Shrimp culture versus crop diversification. Environment, Development and Sustainability. 18(4): 1195-1216.

Kabir, M S, M Salam, A Chowdhury, N Rahman, Iftekharuddaula, M S Rahman, M H Rashid, S S Dipti, S Islam, M A Latif, A K M S Islam, M M Hossain, B Nessa, T H Ansari, M A Ali and J K Biswas. 2015. Rice vision for Bangladesh: 2050 and beyond. Bangladesh Rice Journal. 19: 1-18.

Nishat, A, N, Mukherjee. 2013. Climate change impacts, scenario and vulnerability of Bangladesh. In: R Shaw, F Mallick, A Islam (eds.). Climate Change
Adaptation Actions in Bangladesh. Springer, Tokyo, Japan. pp. 15-41.

Rahman, M A, S Kang, N Nagabhatla and R Macnee. 2017. Impacts of temperature and rainfall variation on rice productivity in major ecosystems of Bangladesh. Agriculture and Food Security. 6(1): p.10.

World Bank. 2013. Turn down the heat: climate extremes, regional impacts, and the case for resilience (1464800561). Retrieved from Washington, D.C., USA: 